\title{
Structural and magnetic features of $\mathrm{La}_{0.7} \mathrm{Sr}_{0.3} \mathrm{Mn}_{1-x} \mathrm{Co}_{x} \mathrm{O}_{3}$ nano-catalysts for ethane combustion and CO oxidation
}

\author{
Ahmad Gholizadeh ${ }^{1, *}$, \\ Azim Malekzadeh ${ }^{2}$, \\ Mahnaz Ghiasi ${ }^{3}$ \\ ${ }^{I}$ School of Physics, Damghan University (DU), Damghan, I.R., Iran \\ ${ }^{2}$ School of Chemistry, Damghan University (DU), Damghan, I.R., Iran \\ ${ }^{3}$ Inorganic Chemistry and Catalysis group, Debye Institute for Nanomaterials Science, Utrecht \\ University, The Netherlands
}

*Corresponding author, Tel-Fax: (+98) 23-35220090; e-mail address: gholizadeh@du.ac.ir; ah_gh1359@yahoo.com 


\begin{abstract}
Structural, magnetic and catalytic properties of $\mathrm{La}_{0.7} \mathrm{Sr}_{0.3} \mathrm{Mn}_{1-x} \mathrm{Co}_{x} \mathrm{O}_{3}(x=0.00,0.25,0.50,0.75$, 1.00) nano-perovskites prepared by the citrate method are investigated. The structural characterization of the compounds by X-ray powder diffraction and using X'Pert package and Fullprof program is an evidence for a monoclinic structure (P21/n space group) with $x=0.50$ and a rhombohedral structure (R-3c space group) for other samples. These results have been confirmed by the FT-IR measurements. Crystallite size of the powders obtained from Halder-Wagner method has been compared with the Scherrer method. The structural and magnetic results suggest the presence of different concentrations of various cations of $\mathrm{Co}^{+2}$, $\mathrm{Co}^{+3}, \mathrm{Co}^{+4}, \mathrm{Mn}^{+4}$ and $\mathrm{Mn}^{+3}$ in the samples. Activation energy, band gap energy, electrical conductivity measurements have been employed to explain catalytic performance of the samples. The results of performance tests show that the sample with $x=0.25$ has the highest catalytic activity for $\mathrm{CO}$ oxidation, whereas, the sample with $x=0.75$ has the highest catalytic activity for $\mathrm{C}_{2} \mathrm{H}_{6}$ combustion.
\end{abstract}

Keywords: Nano-Perovskite; Manganite-Cobaltite; Magnetic Phase Transition; $\mathrm{C}_{2} \mathrm{H}_{6}$ combustion; $\mathrm{CO}$ oxidation.

\title{
1. Introduction
}

Many efforts have been made to reduce the use of precious metals ( $\mathrm{Pt}, \mathrm{Pd}$ and $\mathrm{Rh}$ ) in catalytic systems. Finding a suitable replacement for expensive catalysts used in various industries, including the automotive industry, to further reduce environmental pollutants emitted is a main research in the modern world. High activity in reduction-oxidation (redox) reactions, oxygen storage capability and high flexibility to enter other metals in the structure, have proposed perovskite compounds, $\mathrm{ABO}_{3}$, as a good candidate for this replacement [1]. In addition, being inexpensive and having heat and mechanical resistance properties are some other advantages of these compounds. Among perovskite compounds, lanthalium manganites and cobaltites with the formula of $\mathrm{LaMnO}_{3}$ and $\mathrm{LaCoO}_{3}$ are the famous compounds that are used for complete oxidation of $\mathrm{CO}$ to carbon dioxide [1-2]. 
$\mathrm{LaMn}(\mathrm{Co}) \mathrm{O}_{3}$ with perovskite structure is an insulator-antiferromagnetic system at room temperature due to the absence of $\mathrm{Mn}^{4+}\left(\mathrm{Co}^{4+}\right)$ ions. Upon replacement of $\mathrm{La}^{3+}$ ions with bivalent elements $(\mathrm{Sr}, \mathrm{Ca}, \ldots)$, trivalent $\mathrm{Mn}(\mathrm{Co})$ ions are converted to a mixture of $\mathrm{Mn}^{3+}$ and $\mathrm{Mn}^{4+}\left(\mathrm{Co}^{3+}\right.$ and $\left.\mathrm{Co}^{4+}\right)$ ions. The measurements reported on polycrystalline samples of $\mathrm{La}_{1-y} \mathrm{M}_{y} \mathrm{Mn}(\mathrm{Co}) \mathrm{O}_{3}$, showed insulator-antiferromagnetic behavior in low and high values of $\mathrm{y}$, and metalferromagnetic behavior in samples with $\mathrm{y} \approx 0.3$ [3-4]. In these compounds, the ferromagneticparamagnetic transition associated with a metal-insulator transition below the curie temperature $\left(100<\mathrm{T}_{\mathrm{C}}(\mathrm{K})<350\right)$ have been attributed to double-exchange theory between ions of $\mathrm{Mn}^{3+}-\mathrm{Mn}^{4+}$ $\left(\mathrm{Co}^{3+}-\mathrm{Co}^{4+}\right)$ [5]. Lantalium-strontium cobaltites, like manganites, exhibit complex crystal chemistry, phase separation, but differ from the manganites by the possibility of large oxygen deficiencies and different spin states. Phase separation leading to a glassy ferromagnetic behavior for $\mathrm{La}_{1-x} \mathrm{Sr}_{x} \mathrm{CoO}_{3}$ is a common feature in cobaltites and plays a very important role in their particular magnetic properties.

The electronic and magnetic properties of colossal magnetoresistance (CMR) materials $\mathrm{R}_{1-y} \mathrm{~A}_{y} \mathrm{Mn}_{1-x} \mathrm{~B}_{x} \mathrm{O}_{3}$ (where $\mathrm{R}$ is a trivalent rare earth and $\mathrm{A}$ is a divalent alkali earth, $\mathrm{B}$ is a transition metal) have attracted considerable attention during the past decade [6-9]. Effects of $\mathrm{Mn}$ site substitution on the $\mathrm{T}_{\mathrm{C}}$ and other physical properties of $\mathrm{La}_{0.7} \mathrm{Sr}_{0.3} \mathrm{Mn}_{1-x} \mathrm{~B}_{x} \mathrm{O}_{3}$ with different elements such as $\mathrm{Cr}, \mathrm{Co}, \mathrm{Fe}, \mathrm{Ni}, \mathrm{Mn}$, etc. have been reported [10-13]. In $\mathrm{La}_{1-\mathrm{y}} \mathrm{A}_{y} \mathrm{Mn}_{1-x} \mathrm{Co}_{x} \mathrm{O}_{3}$ compounds, large number of magnetic species present. For example, Co may exist in six possible states, namely, as $\mathrm{Co}^{2+}$ with three different spin states (low spin $t_{2 g}^{6} e_{g}^{1}$ and high spin $t_{2 g}^{5} e_{g}^{2}$ ), as $\mathrm{Co}^{3+}$ with three different spin states (low spin $t_{2 g}^{6} e_{g}^{0}$, intermediate spin $t_{2 g}^{5} e_{g}^{1}$ and high spin $t_{2 g}^{4} e_{g}^{2}$ ) and as $\mathrm{Co}^{4+}$ with three different spin states (low spin $t_{2 g}^{5} e_{g}^{0}$, intermediate spin $t_{2 g}^{4} e_{g}^{1}$ and high spin $t_{2 g}^{3} e_{g}^{2}$ ). On the other hand, Mn may exist in three possible states, namely, as $\mathrm{Mn}^{3+}$ (high spin $t_{2 g}^{3} e_{g}^{1}$ and low spin $\left.t_{2 g}^{4}\right)$ and as $\mathrm{Mn}^{4+}\left(t_{2 g}^{3}\right)$ states. Oxidation states of $\mathrm{Mn}$ and Co depend on the method of preparation. So, understandably, there are many possible ways for Co-Mn interaction to take place via oxygen. Furthermore, all the structural, electronic and magnetic properties of the samples will depend on the nature of the interaction between the Co and $\mathrm{Mn}$ ions via oxygen. Substituting $\mathrm{La}^{3+}$ cations with alkaline-earth cations in $\mathrm{LaMn}_{0.5} \mathrm{Co}_{0.5} \mathrm{O}_{3}$ perovskite increases the average degree of oxidation of $\mathrm{Mn}$ and $\mathrm{Co}$ and leads to a decrease in magnetization and $\mathrm{T}_{\mathrm{C}}$ and a transition to spin-glass or cluster-glass behavior [7]. 
Several investigators have reported that in $\mathrm{ABO}_{3}$ perovskites, the $A$ ions are in general catalytically inactive and the active ions at $B$ position interact with gas molecules readily $[1,5,14-$ 15]. It shoud be noted that substitution of the A-site with a bivalent or a tetravalent cation leads to a different behavior of catylytic activity of manganite-cobaltie compounds. The Sr substitution for $\mathrm{La}$ in $\mathrm{La}_{1-y} \mathrm{~A}_{y} \mathrm{CoO}_{3}$ leads to higher oxidation states of $\mathrm{Co}$, so that the higher the amount of $\mathrm{Sr}$, the higher is the concentration of $\mathrm{Co}^{4+}[5]$. However, since $\mathrm{Co}^{4+}$ is unstable, then oxygen relase can take place ending in the formation of oxygen vacancies that leads to an increase in the catylytic activity. This behavior is explained considering that at high $x$ values, the amount of unstable $\mathrm{Co}^{4+}$ ions and/or of oxygen vacancies increases, which favors the diffusion of lattice oxygen from the bulk to the surface, as charge compensators [5].

The increase in $\mathrm{Sr}$ substitution for three series of $\mathrm{Ln}_{1-\mathrm{y}} \mathrm{Sr}_{\mathrm{y}} \mathrm{NiO}_{3}(\mathrm{Ln}=\mathrm{Pr}, \mathrm{Sm}, \mathrm{Eu})$ provskites showed a strong enhacement in catalytic activity for $\mathrm{CO}$ oxidation and this effect was much more marked in $\operatorname{Pr}_{0.95} \mathrm{Sr}_{0.05} \mathrm{NiO}_{3}$ [5,16]. The changes in the catalytic properties of $\mathrm{AB}_{1-x} \mathrm{~B}_{x}{ }_{x} \mathrm{O}_{3}$ perovskites, substituting cation $\mathrm{B}$ with $\mathrm{B}$ ', can be classified in two categories: geometric and electronic structure of cation B' [6]. The effect of B' substitution on geometric and electronic factors is considered in the calculation of the structural and magnetic changes. Strontium substituted lanthanum manganite, i.e. $\mathrm{La}_{1-x} \mathrm{Sr}_{x} \mathrm{MnO}_{3}$, are known as materials with good oxygen transport properties which make them scientifically interesting as well as technologically useful for many applications [15]. A series of $\mathrm{R}_{1-y} \mathrm{~A}_{\mathrm{y}} \mathrm{Mn}_{1-\mathrm{x}} \mathrm{B}_{\mathrm{x}} \mathrm{O}_{3}$ catalysts have been characterized and reported to show proper activities for $\mathrm{CO}$ oxidation in a temperature range of $50-400{ }^{\circ} \mathrm{C}[2,5-6,8-9,14-16]$. For the $\mathrm{LaBO}_{3}$ (B is a transition metal) perovskite series, $\mathrm{LaMnO}_{3}$ and $\mathrm{LaCoO}_{3}$ proved to be among the most active and $\mathrm{LaCrO}_{3}$ among the least active catalysts for $\mathrm{CO}$ oxidation.

In this paper, we present a systematic study of the structural and magnetic properties of $\mathrm{La}_{0.7} \mathrm{Sr}_{0.3} \mathrm{Mn}_{1-x} \mathrm{Co}_{x} \mathrm{O}_{3}(x=0.00,0.25,0.50,0.75,1.00)$ nanoperovskites prepared by the citrate method. Moreover, the effect of cobalt substitution is investigated on the catalytic activity of $\mathrm{La}_{0.7} \mathrm{Sr}_{0.3} \mathrm{MnO}_{3}$ nanoperovskite for $\mathrm{CO}$ oxidation and ethane combustion that have been not done so far.

\section{Experimental}

\subsection{Sample preparation}


The $\mathrm{La}_{0.7} \mathrm{Sr}_{0.3} \mathrm{Mn}_{1-x} \mathrm{Co}_{x} \mathrm{O}_{3}$ compounds with $x=0.00,0.25,0.50,0.75$, and 1.00 were prepared by the citrate method (Table 1). Firstly, a solution containing appropriate concentrations of metal nitrates $\mathrm{La}\left(\mathrm{NO}_{3}\right)_{3} \cdot 6 \mathrm{H}_{2} \mathrm{O}, \mathrm{Mn}\left(\mathrm{NO}_{3}\right)_{2} \cdot 4 \mathrm{H}_{2} \mathrm{O}, \mathrm{Co}\left(\mathrm{NO}_{3}\right)_{2} \cdot 6 \mathrm{H}_{2} \mathrm{O}, \mathrm{Sr}\left(\mathrm{NO}_{3}\right)_{2}$ and citric acid, equal to the total number of moles of nitrate ions, was evaporated at $60^{\circ} \mathrm{C}$, overnight. The homogeneous sol-like substance subsequently dried at $80^{\circ} \mathrm{C}$, overnight. The resulting spongy and friable materials were completely powdered and kept at $200^{\circ} \mathrm{C}$, overnight. The resulting materials were powdered again and calcined at $900^{\circ} \mathrm{C}$ for $5 \mathrm{~h}$.

\subsection{Materials and physical measurements}

All the chemicals were purchased from Merck and used as received without further purification. The FT-IR spectra of samples were recorded in a Perkin-Elmer FT-IR spectrometer in the wave number range of $450-1650 \mathrm{~cm}^{-1}$. The morphology of the samples was studied by the SEM (Philips XL30) analysis. The particle size of the samples was investigated by the TEM (LEO Model 912AB) analysis. Optical absorption spectra of $\mathrm{La}_{0.7} \mathrm{Sr}_{0.3} \mathrm{Mn}_{1-x} \mathrm{Co}_{x} \mathrm{O}_{3}$ samples have been recorded at room temperature using a HP-UV-Vis system (Agilent8453, model) in the range of 200-1100 nm wavelengths. Band gap energies have been calculated according to Ref. [17]. The X-ray diffraction (XRD) patterns have been recorded using a Bruker AXS diffractometer $\mathrm{D} 8 \mathrm{ADVANCE}$ with $\mathrm{Cu}-\mathrm{K} \alpha$ radiation in the range of $2 \theta=20-80^{\circ}$ at room temperature (RT). XRD profile analysis is a simple and powerful method to evaluate the crystallite size and lattice strain. Two factors determine the breadth of Bragg peak including crystallite size-dependent or strain dependent broadening effects, except instrument-dependent effect. Scherrer's equation show the broadening of the XRD pattern which is attributed to the crystallite size-induced broadening.

$$
D=\frac{0.94 \lambda}{\beta_{h k l} \cos \theta}
$$

Here, $\beta_{h k l}$ is the full-width at half-maximum of the diffraction peak located at $2 \theta=47^{\circ}$. In cases

of isotropic line broadening, the information on strain $(\varepsilon)$ and the crystallite size $(D)$ of the powders have been obtained from $\beta_{h k l}$ and planar spacing $d_{h k l}$ via Halder-Wagner $(\mathrm{H}-\mathrm{W})$ method [18]: 


$$
\left(\frac{\beta_{h k l}^{*}}{d_{h k l}^{*}}\right)^{2}=\left(\frac{1}{D}\right)\left(\frac{\beta_{h k l}^{*}}{d_{h k l}^{*}}\right)+\left(\frac{\varepsilon}{2}\right)^{2}
$$

where $\beta_{h k l}^{*}=\beta_{h k l} \cos \theta / \lambda$ and $d_{h k l}^{*}=2 \sin \theta / \lambda$. Finally, the results of Halder-Wagner method are compared with the Scherrer method.

The hysteresis loops at $10 \mathrm{~K}$ and also temperature dependence of magnetization between 10-400 K was carried out in a SQUID magnetometer (Quantum Design, Inc.). The magnetization curve in high fields can usually be fitted by the empirical formula; law of approach to saturation [19]:

$M(H)=M_{s}\left[1-(a / H)-\left(b / H^{2}\right)-\left(c / H^{3}\right)\right]+\chi H+E H^{1 / 2}$

where $M(H)$ and $M_{S}$ are the magnetization at the field $H$ and the saturation magnetization, respectively.

A quartz tube with two extra pure gold wires as electrode parallel to each other, inserted in either side of inner wall of the cell, was used for electrical conductivity measurements. The electrical conductivity of the samples in air atmosphere (oxidizing conditions) has been studied from lab temperature to a final temperature by randomly increasing the temperature to $350^{\circ} \mathrm{C}$. Reducibility properties of catalysts were studied by electrical conductivity measurements $\sigma_{\mathrm{ox}}$ and $\sigma_{\text {Red }}$, respectively, in oxidation (air) and reduction $\left(6 \% \mathrm{CO}+0.2 \% \mathrm{C}_{2} \mathrm{H}_{6}\right.$ in $\left.\mathrm{Ar}\right)$ atmosphere under steady state conditions at $350^{\circ} \mathrm{C}$ in which the conductivity under the oxidation atmosphere $\left(\sigma_{\mathrm{ox}}\right)$, i.e. air, was reached to a maximum.

\subsection{Catalytic tests}

Catalytic $\mathrm{C}_{2} \mathrm{H}_{6}$ combustion and $\mathrm{CO}$ oxidation tests over $\mathrm{La}_{0.7} \mathrm{Sr}_{0.3} \mathrm{Mn}_{1-x} \mathrm{Co}_{x} \mathrm{O}_{3}$ catalysts were studied in an experimental set-up using a quartz tube, filled with $200 \mathrm{mg}$ of 60-100 mesh sized catalyst supported on a ceramic wool under GHSV of $12,000 \mathrm{~h}^{-1}$. In a typical experiment, a mixture of $\mathrm{CO}$ and $\mathrm{C}_{2} \mathrm{H}_{6}$, more than allowed value defined for environmental $(6 \% \mathrm{CO}+0.2 \%$ $\mathrm{C}_{2} \mathrm{H}_{6}$ ), in $\mathrm{Ar}$ and air, a stoichiometric ratio with respect to oxygen, was passed through the

catalyst bed with a total gas mixture flow rate of $47 \mathrm{~cm}^{3} / \mathrm{min}$ at STP. Catalytic test studies were carried out by temperature rising in randomly intervals from $50^{\circ} \mathrm{C}$ to complete oxidation temperature. The product stream was analyzed by a GC on a FI detector equipped with a 
methanizer. No carbon dioxide was detected using an empty reactor equipped with the ceramic wool.

\section{Results and Discussion}

\subsection{Structural and morphology properties}

X-ray diffraction patterns of $\mathrm{La}_{0.7} \mathrm{Sr}_{0.3} \mathrm{Mn}_{1-x} \mathrm{Co}_{x} \mathrm{O}_{3} \quad(\mathrm{x}=0.00,0.25,0.50,0.75,1.00)$ compounds, is shown in Fig. 1a. As shown in the XRD pattern of the samples with $x=0.25$ and 1.00 , a splitting of the peaks observed at $\sim 33, \sim 41, \sim 58, \sim 68$ and $\sim 78^{\circ}$ is an indication of a rhombohedral system. Nevertheless, a small splitting of the peaks mentioned above has been observed in the XRD pattern of the samples with $x=0.00$ and 0.75. All the peaks in the XRD pattern of the sample with $\mathrm{x}=0.50$ are fully broad. For better comparison, the peak at $\sim 33^{\circ}$ is shown in Fig. 1b. However, fully splitting of the peak at $\sim 33^{\circ}$ observed for the samples with $x=0.25$ and 1.00 is disappeared in the XRD pattern of the samples with $x=0.00,0.50$ and 0.75 . For $x=0.00$ and 0.75 , the peak at $\sim 33^{\circ}$ is singlet, while for $x=0.5$ it is broaden. The XRD pattern of the samples with $x=0.25$ and 1.00 fits with the diffraction pattern of a rhombohedral structure $\mathrm{LaCoO}_{3}$ (JCPDS, 480123). These results suggest a mixture of cubic $\mathrm{LaMnO}_{3}$ (JCPDS, 750440) and rhombohedral $\mathrm{LaCoO}_{3}$ (JCPDS, 480123) for the samples with $\mathrm{x}=0.00$ and 0.75 . It should be noted that the XRD pattern of the sample with $\mathrm{x}=0.50$ is different, while more broadening of the peaks mentioned above and a splitting of the peak at angle $\sim 47^{\circ}$ indicate a structure with lower symmetry.

The XRD data were analyzed using both the commercial X'pert High Score package and Fullprof program. Identification of structure type using X'pert package confirms perovskite structure in all samples without the presence of impure phases. Results of the Rietveld analysis using Fullprof program indicate that all the diffraction peaks of the XRD pattern for the samples with $x=0.00,0.25,0.75,1.00$ can be quite well indexed to the rhombohedral structure (space group R-3c) with reference to hexagonal axes and for the sample with $x=0.50$ can be quite well indexed to the monoclinic structure (space group $\mathrm{P} 2{ }_{1} / \mathrm{n}$ ). To perform a Rietveld refinement good initial values for lattice parameters are needed. The type of space group is obtained from phase analysis of X'pert package. According to previous reports [11, 20], in the case of structure and space group of $\mathrm{La}_{0.7} \mathrm{Sr}_{0.3} \mathrm{MnO}_{3}$ and $\mathrm{La}_{0.7} \mathrm{Sr}_{0.3} \mathrm{CoO}_{3}$ compounds, we can conclude our indexing of 
diffraction patterns in rhombohedra structure with space group R-3c will be true for $x=0.00$ and 1.00 .

The derived lattice parameters of the samples for rhombohedral and monoclinic structures are given in Table 1. It should be noted that if the angle $\alpha$ of the rhombohedral cell be equal $60^{\circ}$ and the bond angle $B-\mathrm{O}-B$ is $180^{\circ}$. Consequently, the lattice of points will be face-centered cubic ( $t$ is equal to 1). Also, the magnitude of the rotation of $\mathrm{BO}_{6}$ can be evaluated from either the angle $\alpha$ of the rhombohedral unit cell written in Table 1. As a result of the rotation (tilting), the B-O-B bond angle $\left(\leq 180^{\circ}\right)$ and $\alpha$ deviate from the ideal perovskite value. From the X-ray diffraction patterns at about $33^{\circ}$ shown in Fig. $1 b$, same tendency is observed for Mn-rich samples ( $x<0.50$ - Co substitution) and Co-rich samples $(x>0.50$ - Mn substitution), namely, an increase of peaks shift to larger $2 \theta$, consequently a decrease of unit cell volume. It should be noted that the structure symmetry of samples decrease with increase of Co substitution up to $x=0.50$. These findings are in accordance to the refined unit cell volume obtained from the rietveld method using Fullprof program summarized in Table 2. The samples with $x=0.25$ and 0.75 have lower unit cell volume due to an increases in the average degree of oxidation of $\mathrm{Mn}$ and Co. Results suggest that the spin states of $t_{2 \mathrm{~g}}$ orbitals for $\mathrm{Co}^{x+}$ and $\mathrm{Mn}^{x+}$ ions may be half-filled or completely filled.

In the following, we aim to suggest charge equilibrium equation for all the samples using structural data and previous reports. However, a correlation with the magnetic data is necessary, as to be discussed later. According to previous reports, charge equilibrium equation for a sample with $x=0.00$ and rhombohedral structure corresponds to $\mathrm{La}_{0.7} \mathrm{Sr}_{0.3} \mathrm{Mn}_{0.3}^{4+} \mathrm{Mn}_{0.7}^{3+} \mathrm{O}_{3}$. In this structure $\mathrm{Mn}$ ions are $\mathrm{Mn}^{3+}(\mathrm{HS})(\mathrm{S}=2: 0.645 \AA)$ and $\mathrm{Mn}^{4+}(\mathrm{S}=3 / 2: 0.53 \AA)$ [21]. There is no apparent linear correlation between the perovskite structure and the substitution degree, and for $x$ $=0.50$ the transformation of the crystal phase occurs. This is due to substitution of $\mathrm{Mn}^{x+}$ ions in the lattice by $\mathrm{Co}^{x+}$ ions. Therefore, all these findings should be related to the ionic radius of each component. Presence of several ionic states $\left(\mathrm{Mn}^{3+}, \mathrm{Mn}^{4+}, \mathrm{Co}^{2+}, \mathrm{Co}^{3+}\right.$ and $\left.\mathrm{Co}^{4+}\right)$ makes it difficult to judge only from the XRD data. The electronic configuration of the Co ions under Co substitution in the Mn-site of the material $\mathrm{La}_{0.7} \mathrm{Sr}_{0.3} \mathrm{MnO}_{3}$ is complicated due to its mixed valence of $\mathrm{Co}^{3+}$ and $\mathrm{Co}^{4+}$. According to previous results [11], a decrease in the lattice constant observed in $\mathrm{La}_{0.7} \mathrm{Sr}_{0.3} \mathrm{Mn}_{1-x} \mathrm{Co}_{x} \mathrm{O}_{3}(x=0.00,0.05$ and 0.10$)$ can be related to the smaller ionic radii of the Co ion as $\mathrm{Co}^{3+}$ in a low spin state $t_{2 g}^{6} e_{g}^{0}$. Investigations of Co $\mathrm{L}_{2,3}$-edge XAS spectra of 
$\mathrm{La}_{0.7} \mathrm{Sr}_{0.3} \mathrm{Mn}_{0.8} \mathrm{Co}_{0.2} \mathrm{O}_{3}$ revealed that cobalt is in the divalent state and consequently, $\mathrm{Mn}$ is in the form of $\mathrm{Mn}^{3+}-\mathrm{Mn}^{4+}$ mixed valence states [22]. Several considerations can be forwarded, however, at this stage: first of all, a peak shift to larger $2 \theta$ with an accompanying decrease of the lattice volume show a decrease of the mean ionic radius of the B cation. In this case, it can be expected that for $x \leq 0.25$, a large reduction of the lattice volume correlates to the presence of Co ions as $\mathrm{Co}^{3+}$ (LS: $0.545 \AA$ ) (Table 2). It is reported that the oxidation states of $\mathrm{Mn}$ and $\mathrm{Co}$ in $\mathrm{LaMn}_{0.5} \mathrm{Co}_{0.5} \mathrm{O}_{3}$, depend on the method of preparation, in particular, the temperature of synthesis or annealing [6, 23-26]. Therefore, from above discussions, the charge equilibrium equation suggested for the sample with $x=0.25$ may be correspond to $\mathrm{La}_{0.7} \mathrm{Sr}_{0.3} \mathrm{Mn}_{0.3}^{4+} \mathrm{Mn}_{0.45}^{3+} \mathrm{Co}_{0.25}^{3+} \mathrm{O}_{3}$. This hypothesis is confirmed by the magnetic and catalytic data presented further.

For $0.25<x \leq 0.5$, a peak shift to smaller $2 \theta$ with an accompanying increase of the lattice volume show an increase of the mean ionic radius of the $\mathrm{B}$ cation (Table 2). It must be taken into account that according to refs. [24, 26], the unit cell volume of $\mathrm{La}_{2} \mathrm{MnCoO}_{6}$ at room temperature is a qualitative indicator of the order parameter of the $\mathrm{Mn}-\mathrm{Co}$ atomic configuration. The valence configuration of this compound in completely ordered phase is $\mathrm{Co}^{2+}-\mathrm{Mn}^{4+}$ whereas in disordered phase, $\mathrm{Mn}^{3+}-\mathrm{Co}^{3+}$ valence states are present. In addition, the $\mathrm{Co}^{2+}$ and $\mathrm{Mn}^{4+}$ ions are ferromagnetically aligned and the $\mathrm{Co}^{2+}$ ions have a large orbital moment. Also, it is known that average ionic radius of $\mathrm{Mn}^{4+}-\mathrm{Co}^{2+}$ is larger than that of $\mathrm{Mn}^{3+}-\mathrm{Co}^{3+}$. Bazuev et al. [7] discovered a high-spin order $\mathrm{Co}^{2+}-\mathrm{Mn}^{4+}$ valence state and low-spin disorder-nonmagnetic $\mathrm{Mn}^{3+}-\mathrm{Co}^{3+}$ ions for samples $\mathrm{La}_{1.25} \mathrm{Sr}_{0.75} \mathrm{CoMnO}_{6}$ with higher and lower Curie temperatures, respectively. The sample with higher Curie temperature is characterized by a smaller volume that can be related to larger average ionic radius of $\mathrm{Mn}^{4+}-\mathrm{Co}^{2+}$ than that of $\mathrm{Mn}^{3+}-\mathrm{Co}^{3+}$. The unit cell volume of the $\mathrm{La}_{1.25} \mathrm{Sr}_{0.75} \mathrm{CoMnO}_{6}$ sample prepared at $750^{\circ} \mathrm{C}$ is smaller than that of the sample prepared at $1300^{\circ} \mathrm{C}$. The reduction in unit cell volume of the high temperature phase can be related to the valence configuration of this compound. $\mathrm{Mn}^{4+}-\mathrm{Co}^{2+}$ and $\mathrm{Mn}^{3+}-\mathrm{Co}^{3+}$ valence states are present in completely ordered and disordered phase, respectively. It was suggested that $\mathrm{La}_{1.25} \mathrm{Sr}_{0.75} \mathrm{Mn}^{4+} \mathrm{Co}_{0.25}^{2+} \mathrm{Co}_{0.75}^{3+} \mathrm{O}_{6}$ and $\mathrm{La}_{1.25} \mathrm{Sr}_{0.75} \mathrm{Mn}_{0.75}^{4+} \mathrm{Mn}_{0.25}^{3+} \mathrm{Co}^{3+} \mathrm{O}_{6}$ should correspond to the ordered and disordered $\mathrm{La}_{1.25} \mathrm{Sr}_{0.75} \mathrm{CoMnO}_{6}$ phases, respectively. Therefore, in case of our sample with $x=0.50$, when replacing $\mathrm{Mn}^{3+}$ by cobalt ions, this ion enters as $\mathrm{Co}^{2+}$, leading to the formation of an equivalent amount of $\mathrm{Mn}^{4+}$ to preserve electro-neutrality of the lattice. In other hands, a $\mathrm{Mn}^{3+}+\mathrm{Co}^{3+} \rightarrow \mathrm{Mn}^{4+}+\mathrm{Co}^{2+}$ type charge redistribution take places from sample 
$x=0.25$ to $x=0.50$. An increase in the lattice volume have been attributed to assumption of substituting $\mathrm{Co}^{2+}$ by $\mathrm{Mn}^{3+}$ due to larger mean ionic radius of $\mathrm{Mn}^{4+}-\mathrm{Co}^{2+}$ with respect to $\mathrm{Mn}^{3+}-\mathrm{Co}^{3+}$. Consequently, from above discussions, the charge equilibrium equation suggested for the sample with $x=0.5$ may correspond to $\mathrm{La}_{0.7} \mathrm{Sr}_{0.3} \mathrm{Mn}_{0.50}^{4+} \mathrm{Co}_{0.20}^{2+} \mathrm{Co}_{0.30}^{3+} \mathrm{O}_{3}$. Again, this hypothesis is confirmed by the magnetic and catalytic data presented further in this work.

Co-rich samples $(x>0.50-$ Mn substitution), $x=0.75$ and 1.00 , stabilize in the rhombohedral structure (space group R-3c) but sample with $x=1.00$ has lower symmetry with respect to the sample with $x=0.75$ due to lower tolerance factor. According to previous reports, the charge equilibrium equation for the sample with $x=1.00$ corresponds to $\mathrm{La}_{0.7} \mathrm{Sr}_{0.3} \mathrm{Co}_{0.3}^{4+} \mathrm{Co}_{0.7}^{3+} \mathrm{O}_{3}$ [20]. It is known that $\mathrm{La}_{0.7} \mathrm{Sr}_{0.3} \mathrm{CoO}_{3-\delta}$ is oxygen deficient and produces a change of $\mathrm{Co}^{3+}$ to $\mathrm{Co}^{2+}$ ions for the charge neutrality with an increase of the mean ionic radius of the B cation. It leads to a peak shift to smaller $2 \theta$ in the XRD pattern of the sample with $x=1.00$ accompanying an increase of the lattice volume.

The change of tolerance factor leads to the observed structural phase transition. As a result, for $x \leq 0.50$, as $\left\langle\mathrm{r}_{B-O}\right\rangle$ increases, so $t$ decrease, at first the rhombohedral structure for $x=0.0$ further distort to rhombohedral for $\mathrm{x}=0.25$ due to higher value of $\alpha$, and then $t$ increase for $x=0.50$, so that rhombohedral structure transforms to monoclinic in which the bending of the B-O-B bond increases and the bond angle further deviates from $180^{\circ}$. For $x>0.50$ inversely, as $\left\langle\mathrm{r}_{B-O}\right\rangle$ decreases, so $t$ increase, the lattice structure transforms from monoclinic to rhombohedral structure.

The results of crystallite size and micro-strain of $\mathrm{La}_{0.7} \mathrm{Sr}_{0.3} \mathrm{Mn}_{1-x} \mathrm{Co}_{x} \mathrm{O}_{3} \quad(x=0.00,0.25$, $0.50,0.75$ and 1.00) samples estimated by the Scherrer and H-W methods are summarized in Table 3. In these two methods, the values of $\beta_{h k l}$ (the full-width at half-maximum of the diffraction peaks) and $\theta$ are selected from the results obtained from rietveld refinement using Fullprof program corresponding to the 15 strongest peaks shown in Fig. $1 a$. The values for the sample with $x=0.50$ are less than those for the other samples.

The H-W method supposes that the "crystallite size" profile contribute to the line broadening by a Lorentzian function and the "strain" profile by a Gaussian function. This method shows that the line broadening is essentially isotropic. However, the advantage of $\mathrm{H}-\mathrm{W}$ method over the Scherrer method is the less weight given to data from reflections at high angles, where the precision is usually lower [17]. Crystallite size obtained from the H-W analysis, 
summarized in Table 3, is more accurate, with all data points touching the fitting line. It should be noted that the crystallite size obtained from these two methods is minimum at about $x=0.50$.

Fig. 3 shows the FT-IR spectra of $\mathrm{La}_{0.7} \mathrm{Sr}_{0.3} \mathrm{Mn}_{1-x} \mathrm{Co}_{x} \mathrm{O}_{3}(x=0.00,0.25,0.50,0.75$ and 1.00) samples. The presence of metal oxygen bonds, i.e., asymmetrical lengthening of the $B-O$ bond of the octahedron $\mathrm{BO}_{6}$ structure could be revealed from the peak positioned at $598 \mathrm{~cm}^{-1}$. Widening of this band and/or the appearance of a shoulder indicates a structure with lower symmetry [6]. The absorption band at $598 \mathrm{~cm}^{-1}$ shifts towards lower wave number values for the samples with $x=0.50$ and 1.00 due to an increases of $e_{\mathrm{g}}$ electrons in the antibonding orbitals. Therefore, bond order would decrease with an increase in the number of $e_{\mathrm{g}}$ electrons. In the other words, the lower frequency band can be assigned to higher deformation mode of $\mathrm{MnO}_{6}$ octahedral having lower symmetry as seen in the FT-IR spectra of the samples with $x=0.50$ and 1.00. Also, it is suggested that the decrease in tolerance factor will increase the $B-O$ bond length. Thus, the lower frequency observed in the samples with $x=0.50$ and 1.00 is due to the decrease of B-O-B bond interaction. The narrow band at $1386 \mathrm{~cm}^{-1}$ might be correspond to $\mathrm{CO}_{3}{ }^{2-}$ groups. The selected area electron diffraction (SAED) pattern in the inset contains information from many GO grains. A typical sharp, polycrystalline ring pattern is obtained TEM micrographs and particle size distribution of $\mathrm{La}_{0.7} \mathrm{Sr}_{0.3} \mathrm{MnO}_{3}$ are shown in Figs. $4 a$ and $4 b$. The selected area electron diffraction (SAED) pattern shown in the inset of Fig. $4 a$ for $\mathrm{La}_{0.7} \mathrm{Sr}_{0.3} \mathrm{MnO}_{3}$ emphasizes the polynanocrystalline feature. Size distribution histogram is fitted by using a log-normal function as follow:

$$
\mathrm{P}(\mathrm{d})=\frac{1}{D \sigma_{d} \sqrt{2 \pi}} \exp \left\{-\frac{1}{2 \sigma_{d}^{2}} \ln ^{2}\left(\frac{D}{D_{T E M}}\right)\right\}
$$

Where $\sigma_{\mathrm{d}}$ is the standard deviation of the diameter and $\mathrm{D}_{\mathrm{TEM}}$ is the mean diameter obtained from the TEM results. The mean diameter of particle size $\mathrm{D}_{\text {TEM }}$ calculated by TEM method is $56 \mathrm{~nm}$.

\subsection{Magnetic measurements}

The hysteresis loops of the $\mathrm{La}_{0.7} \mathrm{Sr}_{0.3} \mathrm{Mn}_{1-x} \mathrm{Co}_{x} \mathrm{O}_{3} \quad(x=0.00,0.25,0.50,0.75$ and 1.00) samples measured at $10 \mathrm{~K}$ are shown in Fig. 5. The S-shaped hysteresis loops show the coercivity field $\mathrm{H}_{\mathrm{C}}$ (intersection with the axis $\mathrm{x}$ ), remanance magnetization $\mathrm{M}_{\mathrm{r}}$ (intersection with the axis $\mathrm{x}$ ) and a saturation magnetization $\mathrm{M}_{\mathrm{S}}$ (obtained from low of approach to saturation). The 
values of $\mathrm{H}_{\mathrm{C}}, \mathrm{M}_{\mathrm{r}}$ and $\mathrm{M}_{\mathrm{S}}$ calculated are summarized in Table 4. The increasing of $\mathrm{H}_{\mathrm{C}}$ with cobalt content may be result of superposition of two contributions, the increase of magnetic domains and the increase of surface anisotropy contribution, which could play a significant role in small particles and thus will influence on coercivity. The $M_{r}$ and $M_{S}$ values for $x \leq 0.50$ are several orders of magnitude larger than that for $x>0.50$.

Under the presence of charge neutralization, charge equilibrium equation for $\mathrm{La}_{0.7} \mathrm{Sr}_{0.3} \mathrm{MnO}_{3}$ is $\mathrm{La}_{0.7} \mathrm{Sr}_{0.3} \mathrm{Mn}_{0.3}{ }^{4+} \mathrm{Mn}_{0.7}{ }^{3+} \mathrm{O}_{3}{ }^{2-}$. These manganese perovskites are mixed valent systems containing $\mathrm{Mn}^{3+}$ and $\mathrm{Mn}^{4+}$ ions. There are two exchange interactions in $\mathrm{La}_{0.7} \mathrm{Sr}_{0.3} \mathrm{MnO}_{3}$ [14], antiferromagnetic coupling between neighboring pairs of $\mathrm{Mn}^{3+}$ ions via $\mathrm{O}_{2}^{-}$and the ferromagnetic coupling between $\mathrm{Mn}^{3+}$ and $\mathrm{Mn}^{4+}$ ions via $\mathrm{O}_{2}^{-}$, to coexist. Results of measuring the saturation magnetization confirms that the sample with $x=0.00$ has a high magnetization value. Hence, the ferromagnetic double-exchange interaction of $\mathrm{Mn}^{4+}-\mathrm{Mn}^{3+}$ is predominant in the $\mathrm{La}_{0.7} \mathrm{Sr}_{0.3} \mathrm{MnO}_{3}$ nanoperovskite. The saturation magnetization for the sample with $x=0.25$ decreases by several orders of magnitude with respect to the sample with $x=0.00$ due to the decrease of double exchange interaction of $\mathrm{Mn}^{4+}-\mathrm{Mn}^{3+}$ [11]. Interestingly the $\mathrm{M}_{\mathrm{S}}$ value for the sample with $x=0.50$ is larger than the sample with $x=0.25$. In accordance to the hypothesis obtained from structural results for the sample with $x=0.25$, Co and $\mathrm{Mn}$ ions corporate into lattice as $\mathrm{Co}^{3+}$ and as $\mathrm{Mn}^{3+}$ and $\mathrm{Mn}^{4+}$, respectively. In the case of the sample with $x=0.50$, Co and $\mathrm{Mn}$ ions corporate into lattice as $\mathrm{Co}^{2+}$ and $\mathrm{Co}^{3+}$ and as $\mathrm{Mn}^{4+}$, respectively. It is known that interactions of $\mathrm{Co}^{2+}-\mathrm{Co}^{3+}$ and $\mathrm{Co}^{3+}-\mathrm{Mn}^{3+}$ are anti-ferromagnetic type while $\mathrm{Co}^{2+}-\mathrm{Mn}^{4+}$ and $\mathrm{Mn}^{4+}-\mathrm{Mn}^{3+}$ are ferromagnetic type [6]. The structural results suggest that for the sample with $x=0.25$ the ferromagnetic interactions of $\mathrm{Mn}^{4+}-\mathrm{Mn}^{3+}$ observed in the sample with $x=0.00$, being progressively replaced by the less effective $\mathrm{Co}^{2+}-\mathrm{Mn}^{4+}$ ferromagnetic and $\mathrm{Co}^{2+}-\mathrm{Co}^{3+}$ and $\mathrm{Mn}^{4+}-\mathrm{Co}^{3+}$ antiferromagnetic interactions. The higher saturation magnetization of the sample with $x=0.50$ by several orders of magnitude with respect to the sample with $x=0.25$ can be related to smaller contribution of antiferromagnetic interactions of $\mathrm{Co}^{3+}-\mathrm{Mn}^{3+}$ in comparison with $\mathrm{Mn}^{4+}-\mathrm{Mn}^{3+}$ ferromagnetic interactions. Therefore, again hypothesis presented from structural calculations is confirmed by the magnetic data.

$\mathrm{Co}^{3+}$ and $\mathrm{Co}^{4+}$ are often found to be in a diamagnetic low spin state $t_{2 g}^{6} e_{g}^{0}$ and high spin state $t_{2 g}^{3} e_{g}^{2}$, respectively [6]. Lantalium-strontium cobaltites for smaller cobalt valencies one obtains weak ferromagnetic semiconductors. In this case, the relatively low value of the mean 
magnetic moment would be a consequence of the presence of diamagnetic $\mathrm{Co}^{\mathrm{III}}$ [20]. It is known that $\mathrm{La}_{0.7} \mathrm{Sr}_{0.3} \mathrm{CoO}_{3-\delta}$ is oxygen deficient giving rise to $\mathrm{Co}^{2+}$ ions for the charge neutrality. Furthermore, there are two antiferromagnetic interactions in $\mathrm{La}_{0.7} \mathrm{Sr}_{0.3} \mathrm{CoO}_{3}$, between neighboring pairs of $\mathrm{Co}^{3+}$ ions via $\mathrm{O}_{2}^{-}$and also between $\mathrm{Co}^{2+}$ and $\mathrm{Co}^{3+}$ ions via $\mathrm{O}_{2}{ }^{-}$[6]. These antiferromagnetic couplings decrease the effect of ferromagnetic coupling between $\mathrm{Co}^{3+}$ and $\mathrm{Co}^{4+}$ and lead to the small magnetization values for the sample with $x=1.00$ [20].

Temperature dependence of magnetization in the range 5-400 $\mathrm{K}$ under applied magnetic field of $0.1 \mathrm{~T}$ for $\mathrm{La}_{0.7} \mathrm{Sr}_{0.3} \mathrm{Mn}_{1-x} \mathrm{Co}_{x} \mathrm{O}_{3}$ samples are shown in Fig. 5. Curie temperature obtained from the critical point in the derivative of the M-T curves is written in Table 4 which clearly shows a non-monotonic dependence of $\mathrm{T}_{\mathrm{C}}$ with Co doping level. Decrease interval of $\mathrm{T}_{\mathrm{C}}$ is about $10 \mathrm{~K}$ for each addition of 0.25 cobalt concentration except first substitution. The transition temperature, $\mathrm{T}_{\mathrm{C}}$, first decreases with an increase in Co doping up to $x=0.50$ and again increases as Co increases. Variation of $\mathrm{T}_{\mathrm{C}}$ with Co doping level can be due to phase separation as observed in variation of metallic behavior discussed further in this work [11,27].

From Fig. 6 it can be concluded that with an increase in the Co content, he M-T curves broaden near the ferromagnetic (FM)-paramagnetic (PM) phase transition temperature, $\mathrm{T}_{\mathrm{C}}$. This could be attributed to the weakening of ferromagnetic (FM) double exchange interactions of $\mathrm{Mn}^{3+}-\mathrm{O}-\mathrm{Mn}^{4+}$ arising from low spin diamagnetic ions (for example $\mathrm{Co}^{3+}: \mathrm{t}^{6}{ }_{2 \mathrm{~g}} \mathrm{e}_{\mathrm{g}}^{0}$ ). In this scenario, the long-range ferromagnetic order collapses and changes to short-range ferromagnetic order that induces cluster type of ferromagnetic order [11,27]. In other words, low spin diamagnetic $\mathrm{Co}^{3+}$ ions take part in super exchange interaction with $\mathrm{Mn}$ and $\mathrm{Co}$ ions leading to coexistence of double exchange interaction and super exchange interaction. The mixed exchange interaction leads to disorder or canting of spins and preventing complete ferromagnetic spin alignments, producing ferromagnetic clusters of finite dimensions which an order below a certain temperature. Also, the spin direction of different ferromagnetic clusters is random, due to random anisotropy.

The analysis of high-temperature susceptibilities $(\mathrm{M} / \mathrm{H})$ of the samples was performed using the Curie-Weiss (CW) law:

$$
\chi(T)=\frac{C}{T-\theta}
$$


where $C\left(=\left(1 / 3 k_{B}\right) \mu_{e f f}^{2}\right), \mu_{e f f}(S)\left(=\mu_{B} g \sqrt{S(S+1)}\right)$ and $\theta$ are the Curie constant, the effective magnetic moment and the paramagnetic $\mathrm{CW}$ temperature, respectively. The fitting of the experimental $(\mathrm{H} / \mathrm{M})(\mathrm{T})$ dependence on the linear function $1 / \chi(T)$ from above equation has shown that the temperature dependence of the inverse susceptibility is linear for the paramagnetic phase and obeys the $\mathrm{CW}$ law (see Fig. 7). The $\mathrm{CW}$ temperatures, $\theta$, calculated as a result of a fitting of $\mathrm{CW}$ law to the experimental data, were found to have a positive sign that is indicative of dominant ferromagnetic interactions. The $\mathrm{C}, \theta, \mathrm{T}_{\mathrm{C}}$ and $\mu_{\mathrm{eff}}$ values for the prepared samples are summarized in Table 4.

Theoretically, in the systems with mixed valance of $\mathrm{Mn}^{3+}$ (concentration 0.7 for sample $\mathrm{x}$ $=0.0$ ) and $\mathrm{Mn}^{4+}$ (concentration 0.3 for sample $\mathrm{x}=0.0$ ) ions, the total magnetic moment $\left(\mu_{\text {tot }}\right)$ can be written in the form of:

$$
\mu_{t o t}^{2}=x \mu_{e f f}^{2}\left(S_{1}\right)+(1-x) \mu_{e f f}^{2}\left(S_{2}\right)
$$

where $S_{1}=2$ and $S_{2}=3 / 2$ are the spins of $\mathrm{Mn}^{3+}$ and $\mathrm{Mn}^{4+}$ ions, respectively, $x=0.7$ is the $\mathrm{Mn}^{3+}$ concentration and g-factor is equal to 2 . The high value of the total moment of $\mu_{t o t}=4.62 \mu_{\mathrm{B}}$ was obtained. The $\mu_{t o t}$ value is between the spin-only values for $\mathrm{Mn}^{3+}\left(4.9 \mu_{\mathrm{B}}\right)$ and $\mathrm{Mn}^{4+}\left(3.87 \mu_{\mathrm{B}}\right)$ ions. In our case, the effective number of Bohr magnetons $\left(\mu_{\text {eff }}\right)$ determined experimentally for $\mathrm{La}_{0.7} \mathrm{Sr}_{0.3} \mathrm{MnO}_{3}$ is approximately equal to the total effective moment value $\left(\mu_{t o t}\right)$.

\subsection{Catalytic Properties}

Catalytic performance (\%) curves of $\mathrm{C}_{2} \mathrm{H}_{6}$ combustion and $\mathrm{CO}$ oxidation for $\mathrm{La}_{0.7} \mathrm{Sr}_{0.3} \mathrm{Mn}_{1-x} \mathrm{Co}_{x} \mathrm{O}_{3}$ catalysts with $\mathrm{x}=0.00,0.25,0.50,0.75$ and 1.00 are shown in Figs. 8a and 8b. Results of the catalytic performance test of $\mathrm{La}_{0.7} \mathrm{Sr}_{0.3} \mathrm{Mn}_{1-x} \mathrm{Co}_{x} \mathrm{O}_{3}$ at $10 \%, 50 \%$ and $95 \%$ of $\mathrm{C}_{2} \mathrm{H}_{6}$ combustion and $\mathrm{CO}$ oxidation are summarized in Table 5. Results show that the catalytic activities for $\mathrm{CO}$ oxidation and $\mathrm{C}_{2} \mathrm{H}_{6}$ combustion do not obey the same order in this series of samples. The sample with $x=0.25$ has a lower temperature for $\mathrm{CO}$ conversion and hence a higher catalytic activity for $\mathrm{CO}$ oxidation. Whereas, the sample with $x=0.75$ has, a lower temperature for $\mathrm{C}_{2} \mathrm{H}_{6}$ conversion, higher catalytic activity for $\mathrm{C}_{2} \mathrm{H}_{6}$ combustion.

The changes in the catalytic properties of $\mathrm{A}\left(\mathrm{B}, \mathrm{B}^{\prime}\right) \mathrm{O}_{3}$ perovskite upon substitution of cation B with B' can be classified in two categories: geometric and electronic structure of cation B'. The effect of Co substitution on geometric factors is considered in the calculation of $t$ factor 
that should be related to structural changes summarized in Table 2. It is suggested that the decrease in tolerance factor will lower the $B-\mathrm{O}-B$ bond strength and promote the formation of oxygen vacancies at the surface and bulk [14]. Thus the decrease in B-O-B bond interaction increases the activity. Consequently, it is expected that the samples with $x=0.25,0.50$ and 1.00 show higher activity for $\mathrm{C}_{2} \mathrm{H}_{6}$ combustion and $\mathrm{CO}$ oxidation. It is known that higher activity should be related to the higher specific surface and lower crystallite sizes. Hence, it can be concluded that higher activity of the samples with $x=0.25,0.50$ and 0.75 can be attributed to the lower crystallite size.

The effect of Co substitution on the catalytic activity might be related to the electronic configuration which intervenes directly in the structural and magnetic changes formed. The electronic configuration cause two different mechanisms, namely, intrafacial and suprafacial processes for $\mathrm{C}_{2} \mathrm{H}_{6}$ combustion and $\mathrm{CO}$ oxidation, respectively, as reported in other works [5,14]. In suprafacial mechanism, adsorbed oxygen and oxygen vacancies are the dominant species participating in $\mathrm{CO}$ oxidation. The main mechanism accepted for $\mathrm{C}_{2} \mathrm{H}_{6}$ combustion is intrafacial at high temperatures. In this mechanism, oxygen supplied by the catalyst and coming from the bulk is responsible for $\mathrm{C}_{2} \mathrm{H}_{6}$ combustion.

In the suprafacial process, the electronic band structure near the Fermi level is believed to play a key role $[9,14]$. The volcano-type dependence between the activity of CO oxidation and the electronic configuration of the transition metal ions (B) was reported by some researchers $[5,7]$. the octahedral environment of the $\mathrm{B}^{3+}$ ions splits into two lower and higher energy levels $t_{2 g}$ and $e_{g}$, respectively, in presence of crystal field. In two cases, the maximum activity in the volcano curves is attained for an occupation of the $e_{g}$ levels of less than one electron whereas the $t_{2 g}$ levels remain half-filled or completely filled [5]. For example, $\mathrm{Mn}^{4+}$ ion configuration in manganites with the half filled $t_{2 \mathrm{~g}}$ orbitals and empty $d_{z^{2}}$ orbital shifts the Fermi level towards the centre of the antibonding $e_{\mathrm{g}}$ orbitals at the surface, which promotes $\mathrm{CO}$ chemisorptions at the surface leading to $\mathrm{CO}$ oxidation [7-10]. Finally, we may conclude from the structural, magnetic, and catalytic variations of the samples with $x=0.25$ and 0.75 that spin states of $t_{2 \mathrm{~g}}$ orbitals for $\mathrm{Co}^{x+}$ and $\mathrm{Mn}^{x+}$ ions may be in the states of half-filled or completely filled that can explain decreases of the magnetization by several orders of magnitude with respect to the samples with $x=0.00$ and 0.50 . 
The variations of electrical conductivity $(\sigma)$ versus temperature $(T)$ obey an Arrhenius equation as follows:

$$
(\sigma)=\sigma_{\circ} \exp \left(-\frac{E_{c}}{R T}\right)
$$

Plotting $\ln \sigma$ vs. $1 / \mathrm{T}$, the equation represents a straight line with a slope of $-\mathrm{E}_{\mathcal{c}} / \mathrm{R}$ and a $\mathrm{y}$-intercept of $\ln \sigma_{\mathrm{o}}$. Results of activation energy $\left(E_{\mathrm{c}}\right)$, band gap energy $\left(E_{\mathrm{g}}\right)$, and measured electrical conductivity $\left(\sigma_{\mathrm{Ox}}, \sigma_{\mathrm{Red}}\right.$ and $\left.\sigma_{\mathrm{Ox}} / \sigma_{\mathrm{Red}}\right)$ are summarized in Table 6. A depletion of charge carriers takes place upon switching from air atmosphere to $6 \% \mathrm{CO}+0.2 \% \mathrm{C}_{2} \mathrm{H}_{6}$ in $\mathrm{Ar}$ atmosphere, decreasing the electrical conductivity of the catalysts. Electric conductivity, however, increases to the first level upon switching the conditions to oxidation atmosphere. These results indicate that the mobile oxy-anions are the main part of the charge carriers. Also, the catalysts are completely suitable for giving and gaining oxygen under reduction and oxidation conditions, respectively. This property makes the catalysts suitable for oxidation of adsorbed species on the catalyst surface. Results also suggest that the conductivity of the lanthanum manganites is somehow affected by Co substitution in the way we did in this study. Also, Eg values show a increase up to $\mathrm{x}=0.50$ and then decrease with more increase of Co content. According to previous report by Kundu et al. [27], the increase either $\mathrm{Mn}$ content in $\mathrm{Nd}_{0.5} \mathrm{Sr}_{0.5} \mathrm{CoO}_{3}$ or $\mathrm{Co}$ content in $\mathrm{Nd}_{0.5} \mathrm{Sr}_{0.5} \mathrm{MnO}_{3}$ increases the resistivity of the samples. This is attributed to the effect of phase separation which reported in $\mathrm{Nd}_{0.5} \mathrm{Sr}_{0.5} \mathrm{Co}_{1-y} \mathrm{Mn}_{\mathrm{y}} \mathrm{O}_{3}$ compounds [27]. The samples with $x=0.75$ and 1.00 have lower $\mathrm{E}_{\mathrm{g}}$ indicating more metallic behavior with respect to the other samples. Therefore, the non-uniformly changes of $\sigma_{\mathrm{ox}} / \sigma_{\mathrm{Red}}, \mathrm{E}_{\mathrm{c}}$ and $\mathrm{E}_{\mathrm{g}}$ values with increasing Co substitution can be related to phase separation due to the presence of different concentration of various cations of $\mathrm{Co}^{+2}, \mathrm{Co}^{+3}, \mathrm{Co}^{+4}, \mathrm{Mn}^{+4}$ and $\mathrm{Mn}^{+3}$ in the samples. Also, the variation of $\mathrm{T}_{\mathrm{C}}$ discussed former in this work was attributed to the presence of phase separation observed in samples.

Consequently, the sample with $x=0.75$ has low $\mathrm{E}_{\mathrm{g}}$ and high $\sigma_{\mathrm{ox}} / \sigma_{\mathrm{Red}}$ which make it favorable for reducibility [7,8]. According to the catalytic performance tests, this sample shows the highest catalytic activity for $\mathrm{C}_{2} \mathrm{H}_{6}$ combustion (see Tables 5 and 6). However, the sample with $x=0.25$ has low $\mathrm{E}_{\mathrm{c}}$ value and is more favorable one for the $\mathrm{CO}$ oxidation. This means that the sample with $x=0.25$ provides a better condition for transfer of oxygen to the adsorbed $\mathrm{CO}$ on the catalyst surface at lower temperature with respect to the other catalysts. 


\section{Conclusion}

The structural, magnetic and catalytic properties of $\mathrm{La}_{0.7} \mathrm{Sr}_{0.3} \mathrm{Mn}_{1-x} \mathrm{Co}_{x} \mathrm{O}_{3}(x=0.00,0.25$, $0.50,0.75$ and 1.00) samples are investigated. The structural characterization of the compounds by X-ray powder diffraction and using X'Pert package and Fullprof program is an evidence for a monoclinic structure (P21/n space group) with $x=0.50$ and a rhombohedral structure (R-3c space group) for the other samples. These results have been confirmed by FT-IR measurements. The samples with $x=0.25$ and 0.75 have lower unit cell volume due to increases the average degree of oxidation of $\mathrm{Mn}$ and Co. Also, the structural results suggest that spin states of $t_{2 \mathrm{~g}}$ orbitals for $\mathrm{Co}^{x+}$ and $\mathrm{Mn}^{x+}$ ions may be in the states of half-filled or completely filled that can explain decreases of the magnetization of these samples by several orders of magnitude with respect to the samples with $x=0.00$ and 0.50 . The structural and magnetic results suggest the presence of different concentrations of various cations of $\mathrm{Co}^{+2}, \mathrm{Co}^{+3}, \mathrm{Co}^{+4}, \mathrm{Mn}^{+4}$ and $\mathrm{Mn}^{+3}$ in the samples. This confirms the presence of the ferromagnetic interactions of $\mathrm{Co}^{2+}-\mathrm{Mn}^{4+}$ and $\mathrm{Co}^{2+}-\mathrm{Mn}^{4+}$ for $x \leq 0.5$ that is progressively replaced by the less effective $\mathrm{Co}^{2+}-\mathrm{Co}^{3+}$ and $\mathrm{Mn}^{4+}$ $\mathrm{Co}^{3+}$ interactions for $x>0.5$. Results of the catalytic performance tests of $\mathrm{La}_{0.7} \mathrm{Sr}_{0.3} \mathrm{Mn}_{1-x} \mathrm{Co}_{x} \mathrm{O}_{3}$ catalysts measured under similar conditions, show that the sample with $x=0.25$ has lower temperature of $\mathrm{CO}$ conversion and hence higher catalytic activity for $\mathrm{CO}$ oxidation. In comparison, the sample with $x=0.75$ has lower temperature of $\mathrm{C}_{2} \mathrm{H}_{6}$ conversion and higher catalytic activity for $\mathrm{C}_{2} \mathrm{H}_{6}$ combustion. The lower activation energy and unit cell volume observed for the sample with $x=0.25$ suggest that this sample is more favorable for $\mathrm{CO}$ oxidation. This means that the sample with $x=0.25$ provide a better condition for transfer of oxygen to the adsorbed $\mathrm{CO}$ on the catalyst surface at lower temperature with respect to the other catalysts. However, the higher $\sigma_{\mathrm{ox}} / \sigma_{\text {Red }}$ observed for the sample with $x=0.75$ suggest that this sample is more favorable for reducibility and has the best catalytic performance for $\mathrm{C}_{2} \mathrm{H}_{6}$ combustion.

\section{Acknowledgment}


The finantial support of the Iran National Science Foundatin (INSF) under grant number 90007228 is acknowledged. The authors wish to thank Frances Hellman Group at the University of California-Berkeley for their help in magnetic measurements.

\section{References}

[1] H. Tanaka, M. Misono, Advances in designing perovskite catalysts, Solid. State. Mater. Sci. 5 (2001) 381-387.

[2] P. Ciambelli, S. Cimino, S. De Rossi, L. Lisi, G. Minelli, P. Porta, G. Russo, $\mathrm{AFeO}_{3}(\mathrm{~A}=\mathrm{La}$, $\mathrm{Nd}, \mathrm{Sm})$ and $\mathrm{LaFe}_{1-x} \mathrm{Mg}_{x} \mathrm{O}_{3}$ perovskites as methane combustion and $\mathrm{CO}$ oxidation catalysts Appl. Catal. B. 29 (2001) 239-250.

[3] C. Zener, Interaction between the d Shells in the Transition Metals, J. Phys. Rev. 81 (1951) 440-444.

[4] J. B. Goodenough, Theory of the Role of Covalence in the Perovskite-Type Manganites [La, $\mathrm{M}(\mathrm{II})] \mathrm{MnO}_{3}$, J. Phys. Rev. 100 (1955) 564-573.

[5] M. A. Peña and J. L. G. Fierro, Chemical Structures and Performance of Perovskite Oxides, Chem. Rev. 101 (2001) 1981-2017.

[6] G. Pecchi, C. Campos, O. Peña, L. E. Cadus, Structural, magnetic and catalytic properties of perovskite-type mixed oxides $\mathrm{LaMn}_{1-\mathrm{x}} \mathrm{Co}_{\mathrm{x}} \mathrm{O}_{3}(\mathrm{x}=0.0,0.1,0.3,0.5,0.7,0.9,1.0)$, J. Mol. Catal. A: Chem. 282 (2008) 158-166.

[7] G.V. Bazuev, A.V.Korolyov , M.A.Melkozyorova, T.I. Chupakhina, Magnetic phases in lanthanum-strontium manganite-cobaltite $\mathrm{La}_{1.25} \mathrm{Sr}_{0.75} \mathrm{MnCoO}_{6}$, J. Magn. Magn. Mater. 322 (2010) 494-499.

[8] M. Lotfi, A. Gholizadeh, A. Malekzadeh, Structural and Redox Properties of the La1${ }_{x} \mathrm{Sr}_{x} \mathrm{Mn}_{0.5} \mathrm{Co}_{0.5} \mathrm{O}_{3}(\mathrm{x}=0.0,0.1,0.2,0.3,0.4,0.5)$ Nano-Catalysts for Carbon Monoxide Oxidation, Journal of Advanced Materials and Processing, 2 (2014) 65-70.

[9] Ahmad Gholizadeh, Azim Malekzadeh, Mahnaz Ghiasi, Structural, magnetic and catalytic properties of Co substituted manganite nano-perovskites, Bulgarian Chemical Communications, 47 (2015) 771-798.

[10] T. M. Tank, D. Bhargava, S. P. Sanyal, Effect of Cr doping in Structure and Magnetotransport Properties of $\left(\mathrm{La}_{0.67} \mathrm{Sr}_{0.33}\right) \mathrm{MnO}_{3}$, Advances in Physics Theories and Applications, 19 (2013) 130-135. 
[11] P. Zhang, H. Yang, S. Zhang, H. Ge, S. Hua, Magnetic and magnetocaloric properties of perovskite $\mathrm{La}_{0.7} \mathrm{Sr}_{0.3} \mathrm{Mn}_{1-\mathrm{x}} \mathrm{Co}_{\mathrm{x}} \mathrm{O}_{3}$, Physica B 410 (2013) 1-4.

[12] C.P. Reshmia, S. S. Pillai, K.G. Suresh, M. R. Varma, Near room temperature magnetocaloric properties of $\mathrm{Fe}$ substituted $\mathrm{La}_{0.67} \mathrm{Sr}_{0.33} \mathrm{MnO}_{3}$, Materials Research Bulletin 48 (2013) 889-894.

[13] M. H. Phan, N. Duc Tho, N. Chau, S. C. Yu, M. Kurisu, Large magnetic entropy change above $300 \mathrm{~K}$ in a colossal magnetoresistive material $\mathrm{La}_{0.7} \mathrm{Sr}_{0.3} \mathrm{Mn}_{0.98} \mathrm{Ni}_{0.02} \mathrm{O}_{3}$, J. Appl. Phys. 97 (2005)103901.

[14] R.G. Shetkar and A.V. Salker, Electrical, Magnetic and Catalytic Investigations on Some Manganite Perovskites Prepared by Combustion Method, J. Mater. Sci. Technol. 26 (2010) 1098-1102.

[15] Ehsan Frozandeh-Mehr, Azim Malekzadeh, Mahnaz Ghiasi, Ahmad Gholizadeh, Yadollah Mortazavi, Abbasali Khodadadi, Effect of partial substitution of lanthanum by strontium or bismuth on structural features of the lanthanum manganite nanoparticles as a catalyst for carbon monoxide oxidation, Catal. Commun. 28 (2012) 32-37.

[16] H. He, H. X. Dai, C. T. Au, An investigation on the utilization of perovskite-type oxides $\mathrm{La}_{1-\mathrm{x}} \mathrm{Sr}_{\mathrm{x}} \mathrm{MO}_{3}\left(\mathrm{M}=\mathrm{Co}_{0.77} \mathrm{Bi}_{0.20} \mathrm{Pd}_{0.03}\right)$ as three-way catalysts, Applied Catalysis $\mathrm{B}$ : Environmental 33 (2001) 65.

[17] A. Gholizadeh, N.Tajabor , Influence of $\mathrm{N}_{2}$ and Ar-ambient annealing on the physical properties of $\mathrm{SnO}_{2}$ :Co transparent conducting films, Mater. Sci. Semicond. Process. 13, (2010) 162-166.

[18] A. Gholizadeh, X-Ray Peak Broadening Analysis in $\mathrm{LaMnO}_{3+\delta}$ Nano-Particles with Rhombohedral Crystal Structure, Journal of Advanced Materials and Processing, 3 (2015) 71-83.

[19] R. Groessinger, A Critical Examination of the Law of Approach to Saturation, phys. stat. sol. (a) 66 (1981) 665-674.

[20] P. Ravindran, P. A. Korzhavyi, H. Fjellvåg, Electronic structure, phase stability, and magnetic properties of $\mathrm{La}_{1-x} \mathrm{Sr}_{x} \mathrm{CoO}_{3}$ from first-principles full-potential calculations, Phys. Rev. B, 60 (1999)16 424.

[21] V. Dyakonov, A. Ślawska-Waniewska, N. Nedelko, E. Zubov, V. Mikhaylov, K. Piotrowski, A. Szytu, S. Baran, W. Bazela, Z. Kravchenko, P. Aleshkevich, A. Pashchenko, K. Dyakonov, V. Varyukhin, H. Szymczak, Magnetic, resonance and transport properties of nanopowder of $\mathrm{La}_{0.7} \mathrm{Sr}_{0.3} \mathrm{MnO}_{3}$ manganites, Journal of Magnetism and Magnetic Materials 322 (2010) 3072-3079. 
[22] J. H. Park, S.-W. Cheong, and C. T. Chen, Double-exchange ferromagnetism in $\mathrm{LaMn}_{1-}$ ${ }_{x} \mathrm{Co}_{x} \mathrm{O}_{3}$, Phys. Rev. B 55 (1997) 11072.

[23] T. Kyomen, R. Yamazaki, M. Itoh, Correlation between Magnetic Properties and Mn/Co Atomic Order in $\mathrm{LaMn}_{0.5} \mathrm{Co}_{0.5} \mathrm{O}_{3+\delta}$ : I. Second-Order Nature in $\mathrm{Mn} / \mathrm{Co}$ Atomic Ordering and Valence State, Chem. Mater. 15 (2003) 4798.

[24] V. L. J. Joly, Y. K. Khollam, P. A. Joy, C. S. Gopinath, S. K. Date, Unusual charge disproportion at ion and associated magnetic behaviour in nanocrystalline $\mathrm{LaMn}_{0.5} \mathrm{Co}_{0.5} \mathrm{O}_{3}$, J. Phys.: Condens. Matter 13 (2001) 11001.

[25] R. I. Dass, J. B. Goodenough, Multiple magnetic phases of $\mathrm{La}_{2} \mathrm{CoMnO}_{6-\delta}(0<\delta<0.05)$, Phys. Rev. B 67 (2002) 014401.

[26] P. A. Joy, Y. K. Khollam, S. K. Date, Spin states of Mn and Co in $\mathrm{LaMn}_{0.5} \mathrm{Co}_{0.5} \mathrm{O}_{3}$, Phys. Rev. B 62 (2000) 8608.

[27] S. Kundu, T.K. Nath, Effect of Mn doping on magnetic and transport properties of $\mathrm{Nd}_{0.5} \mathrm{Sr}_{0.5} \mathrm{Co}_{1-\mathrm{y}} \mathrm{Mn}_{\mathrm{y}} \mathrm{O}_{3}$, Journal of Magnetism and Magnetic Materials 325 (2013) 1-6.

Table 1: Moles of the metal nitrates for the preparation of $\mathrm{La}_{0.7} \mathrm{Sr}_{0.3} \mathrm{Mn}_{1-x} \mathrm{Co}_{x} \mathrm{O}_{3}$ samples ${ }^{\mathrm{a}}$.

\begin{tabular}{c|cccc}
\hline Sample & $\mathrm{La}\left(\mathrm{NO}_{3}\right)_{3} \cdot 6 \mathrm{H}_{2} \mathrm{O}$ & $\mathrm{Mn}\left(\mathrm{NO}_{3}\right)_{2} \cdot 4 \mathrm{H}_{2} \mathrm{O}$ & $\mathrm{Co}\left(\mathrm{NO}_{3}\right)_{2} \cdot 6 \mathrm{H}_{2} \mathrm{O}$ & $\mathrm{Sr}\left(\mathrm{NO}_{3}\right)_{2}$ \\
\hline $\mathbf{x}=\mathbf{0 . 0 0}$ & 0.0093 & 0.013 & - & 0.004 \\
$\mathbf{x}=\mathbf{0 . 2 5}$ & 0.0092 & 0.0099 & 0.0033 & 0.004 \\
$\mathbf{x}=\mathbf{0 . 5 0}$ & 0.0092 & 0.0066 & 0.0066 & 0.0039 \\
$\mathbf{x}=\mathbf{0 . 7 5}$ & 0.00915 & 0.0033 & 0.0098 & 0.0039 \\
$\mathbf{x}=\mathbf{1 . 0 0}$ & 0.0091 & - & 0.013 & 0.0039 \\
\hline
\end{tabular}

${ }^{\text {a }}$ Mole of the citric acid is considered to be 0.0615 in all preparation 
Table 2: The structure type and unit cell parameters of $\mathrm{La}_{0.7} \mathrm{Sr}_{0.3} \mathrm{Mn}_{1-x} \mathrm{Co}_{x} \mathrm{O}_{3}$ samples.

\begin{tabular}{|c|c|c|c|}
\hline Sample & $\begin{array}{c}\text { Structure } \\
\text { (space group) }\end{array}$ & lattice Parameters & $\begin{array}{c}\mathrm{V} \\
\left(\AA^{3}\right)\end{array}$ \\
\hline $\mathbf{x}=\mathbf{0 . 0 0}$ & $\begin{array}{l}\text { Rhombohedral } \\
\qquad(\mathrm{R}-3 \mathrm{c})\end{array}$ & $\begin{array}{l}a=b=c=5.457 \AA \\
\alpha=\beta=\gamma=60.38^{\circ}\end{array}$ & 115.89 \\
\hline$x=0.25$ & $\begin{array}{l}\text { Rhombohedral } \\
\qquad(\mathrm{R}-3 \mathrm{c})\end{array}$ & $\begin{array}{l}a=b=c=5.374 \AA \\
\alpha=\beta=\gamma=60.71^{\circ}\end{array}$ & 111.55 \\
\hline$x=0.50$ & $\begin{array}{l}\text { Monoclinic } \\
\text { (P 21/n) }\end{array}$ & $\begin{aligned} a & =5.327 \AA, b=5.404 \AA \\
c & =7.164 \AA, \beta=94.75^{\circ}\end{aligned}$ & 205.52 \\
\hline$x=0.75$ & $\begin{array}{l}\text { Rhombohedral } \\
\text { (R-3c) }\end{array}$ & $\begin{array}{l}a=b=c=5.414 \AA \\
\alpha=\beta=\gamma=60.25^{\circ}\end{array}$ & 112.88 \\
\hline$x=1.00$ & $\begin{array}{l}\text { Rhombohedral } \\
\qquad(\mathrm{R}-3 \mathrm{c})\end{array}$ & $\begin{array}{l}a=b=c=5.457 \AA \\
\alpha=\beta=\gamma=60.60^{\circ}\end{array}$ & 116.49 \\
\hline
\end{tabular}

Table 3: The values of crystallite size and strain for $\mathrm{La}_{0.7} \mathrm{Sr}_{0.3} \mathrm{Mn}_{1-x} \mathrm{Co}_{x} \mathrm{O}_{3}$ samples obtained from Scherrer and $\mathrm{H}-\mathrm{W}$ methods.

\begin{tabular}{c|ccc}
\hline Sample & $\begin{array}{c}\mathrm{D}_{\text {scherrer }} \\
(\mathrm{nm})\end{array}$ & $\begin{array}{c}\mathrm{D}_{\mathrm{H}-\mathrm{W}} \\
(\mathrm{nm})\end{array}$ & $\begin{array}{c}\varepsilon_{\mathrm{H}-\mathrm{W}} * 10^{3} \\
(\text { no unit })\end{array}$ \\
\hline $\mathbf{x = \mathbf { 0 . 0 0 }}$ & 25.2 & 27.4 & 8.2 \\
$\mathbf{x}=\mathbf{0 . 2 5}$ & 31.8 & 23.5 & 9.3 \\
$\mathbf{x}=\mathbf{0 . 5 0}$ & 18.5 & 22.0 & 12.7 \\
$\mathbf{X}=\mathbf{0 . 7 5}$ & 23.8 & 24.27 & 3.2 \\
$\mathbf{x}=\mathbf{1 . 0 0}$ & 29.1 & 25.8 & 3.9 \\
\hline
\end{tabular}


Table 4: Magnetic results of $\mathrm{La}_{0.7} \mathrm{Sr}_{0.3} \mathrm{Mn}_{1-x} \mathrm{Co}_{x} \mathrm{O}_{3}$ Samples.

\begin{tabular}{c|ccccccc}
\hline Sample & $\begin{array}{c}\mathbf{M}_{\mathbf{S}}(\mathbf{1 0} \mathbf{K}) \\
\left(\boldsymbol{\mu}_{\mathbf{B}} / \mathbf{f . u .}\right)\end{array}$ & $\begin{array}{c}\mathbf{H}_{\mathbf{C}}(\mathbf{1 0} \mathbf{K}) \\
(\mathbf{O e})\end{array}$ & $\begin{array}{c}\mathbf{M}_{\mathbf{r}}(\mathbf{1 0 ~ K}) \\
(\mathbf{e m u} / \mathbf{g})\end{array}$ & $\begin{array}{c}\mathbf{T}_{\mathbf{C}} \\
(\mathbf{K})\end{array}$ & $\begin{array}{c}\boldsymbol{\Theta} \\
(\mathbf{K})\end{array}$ & $\begin{array}{c}\mathbf{C} \\
(\mathbf{e m u . K} / \mathbf{m o l} . \mathbf{O})\end{array}$ & $\begin{array}{c}\boldsymbol{\mu}_{\mathrm{eff}} \\
\left(\boldsymbol{\mu}_{\mathbf{B}}\right)\end{array}$ \\
\hline $\mathbf{x}=\mathbf{0 . 0 0}$ & 2.758 & 173 & 20.19 & 330 & 349 & 2.585 & 4.55 \\
$\mathbf{x}=\mathbf{0 . 2 5}$ & 0.262 & 2730 & 3.52 & 180 & 246 & 0.335 & 1.64 \\
$\mathbf{x}=\mathbf{0 . 5 0}$ & 2.323 & 3000 & 24.53 & 171 & 194 & 3.855 & 5.55 \\
$\mathbf{x}=\mathbf{0 . 7 5}$ & 0.050 & 4775 & 0.60 & 183 & 241 & 0.136 & 1.04 \\
$\mathbf{x}=\mathbf{1 . 0 0}$ & 0.043 & 4530 & 0.45 & 191 & 209 & 0.107 & 0.93 \\
\hline
\end{tabular}

Table 5: Catalytic performance (\%), $\mathrm{C}_{2} \mathrm{H}_{6}$ combustion and $\mathrm{CO}$ oxidation temperatures $\left({ }^{\circ} \mathrm{C}\right)$, for $\mathrm{La}_{0.7} \mathrm{Sr}_{0.3} \mathrm{Mn}_{1-x} \mathrm{Co}_{x} \mathrm{O}_{3}$ Samples.

\begin{tabular}{c|ccc|ccc}
\hline \multirow{2}{*}{ Sample } & \multicolumn{3}{|c|}{ Temperature of CO conversion $\left({ }^{\circ} \mathrm{C}\right)$} & \multicolumn{4}{|c}{ Temperature of $\mathrm{C}_{2} \mathrm{H}_{6}$ conversion $\left({ }^{\circ} \mathrm{C}\right)$} \\
& $10 \%$ & $50 \%$ & $95 \%$ & $10 \%$ & $50 \%$ & $95 \%$ \\
\hline $\mathbf{x}=\mathbf{0 . 0 0}$ & 186 & 222 & 283 & 92 & 330 & 480 \\
$\mathbf{x}=\mathbf{0 . 2 5}$ & 100 & 160 & 190 & 272 & 476 & 485 \\
$\mathbf{x}=\mathbf{0 . 5 0}$ & 181 & 187 & 203 & 110 & 363 & 430 \\
$\mathbf{x}=\mathbf{0 . 7 5}$ & 152 & 167 & 174 & 120 & 343 & 382 \\
$\mathbf{x = 1 . 0 0}$ & 195 & 212 & 226 & 94 & 332 & 485 \\
\hline
\end{tabular}

Table 6: Electric conductivity ${ }^{\mathrm{a}}$ and band gap energies of the prepared samples.

\begin{tabular}{|c|c|c|c|c|c|}
\hline Sample & $\begin{array}{c}\sigma_{0 x} \times 10^{5} \\
\left(\Omega^{-1}\right)\end{array}$ & $\begin{array}{c}{ }^{\mathrm{b}} \sigma \operatorname{Red} \times 10^{5} \\
\left(\Omega^{-1}\right)\end{array}$ & $\sigma_{0 x} / \sigma_{\text {Red }}$ & $\begin{array}{c}\mathbf{E}_{\mathrm{c}} \\
(\mathrm{kCal} / \mathrm{mol})\end{array}$ & $\begin{array}{l}\mathbf{E g}_{\mathbf{g}} \\
(\mathbf{e v})\end{array}$ \\
\hline$x=0.00$ & 3.30 & 4.19 & 0.786 & 0.87 & 1.66 \\
\hline$x=0.25$ & 1.50 & 1.38 & 1.087 & 0.82 & 1.76 \\
\hline$x=0.50$ & 2.04 & 2.14 & 0.953 & 1.46 & 1.75 \\
\hline$x=0.75$ & 3.80 & 2.56 & 1.484 & 2.17 & 1.15 \\
\hline$x=1.00$ & 170.51 & 144.65 & 1.179 & 1.42 & 0.99 \\
\hline
\end{tabular}

${ }^{\mathrm{a}}$ Electric conductivity was measured at $350^{\circ} \mathrm{C}$ in which the conductivity under the oxidation atmosphere $\left(\sigma_{\mathrm{ox}}\right)$, i.e. air, was reached to a maximum. $\mathrm{b}_{\sigma_{\mathrm{ox}}}$ and $\sigma_{\mathrm{Red}}$ are the conductivity under the oxidation (air) and reduction atmosphere $\left(6 \% \mathrm{CO}+0.2 \% \mathrm{C}_{2} \mathrm{H}_{6}\right.$ in $\left.\mathrm{Ar}\right)$, respectively. 


\section{Figure captions}

Fig. 1: Rietveld analysis of the X-ray diffraction patterns for $\mathrm{La}_{0.7} \operatorname{Sr}_{0.3} \mathrm{Mn}_{1-x} \mathrm{Co}_{x} \mathrm{O}_{3}(x=0.00$, $0.25,0.50,0.75$ and 1.00). The circle signs represent the raw data. The solid lines represent the calculated profile. Vertical bars indicate the position of Bragg peaks for the samples with the rhombohedral structure (Space Group R -3 c) and for the sample with $x=0.5$ and monoclinic structure (Space Group $\mathrm{P} 2{ }_{1} / \mathrm{n}$ ). The lowest curve is the difference between the observed and the calculated patterns. The X-ray diffraction patterns for all the samples at $\sim 33^{\circ}$ are shown in the inset of $x=0.75$.

Fig. 2: Fitted curves of the $H-W$ analysis for sample $x=0$.

Fig. 3: FT-IR spectra of $\mathrm{La}_{0.7} \mathrm{Sr}_{0.3} \mathrm{Mn}_{1-x} \mathrm{Co}_{x} \mathrm{O}_{3}$ samples.

Fig. 4: (a) TEM micrograph (inset: SAED pattern) and (b) size distribution histograms for $\mathrm{La}_{0.7} \mathrm{Sr}_{0.3} \mathrm{MnO}_{3}$.

Fig. 5: The hystersis loops $(\mathrm{M}-\mathrm{H})$ at $10 \mathrm{~K}$ for $\mathrm{La}_{0.7} \mathrm{Sr}_{0.3} \mathrm{Mn}_{1-x} \mathrm{Co}_{x} \mathrm{O}_{3}$ samples.

Fig. 6: The magnetization curves versus temperature measured under applied magnetic field 0.1T for $\mathrm{La}_{0.7} \mathrm{Sr}_{0.3} \mathrm{Mn}_{1-\mathrm{x}} \mathrm{Co}_{\mathrm{x}} \mathrm{O}_{3}$.

Fig. 7: The fitting of temperature dependence of the inverse susceptibility (H/M) for paramagnetic phase of $\mathrm{La}_{0.7} \mathrm{Sr}_{0.3} \mathrm{Mn}_{1-x} \mathrm{Co}_{x} \mathrm{O}_{3}$ samples.

Fig. 8: Catalytic performance curves of $\mathrm{La}_{0.7} \mathrm{Sr}_{0.3} \mathrm{Mn}_{1-\mathrm{x}} \mathrm{Co}_{\mathrm{x}} \mathrm{O}_{3}$ for $(a) \mathrm{CO}$ oxidation and $(b) \mathrm{C}_{2} \mathrm{H}_{6}$ combustion. 
Fig. 1:

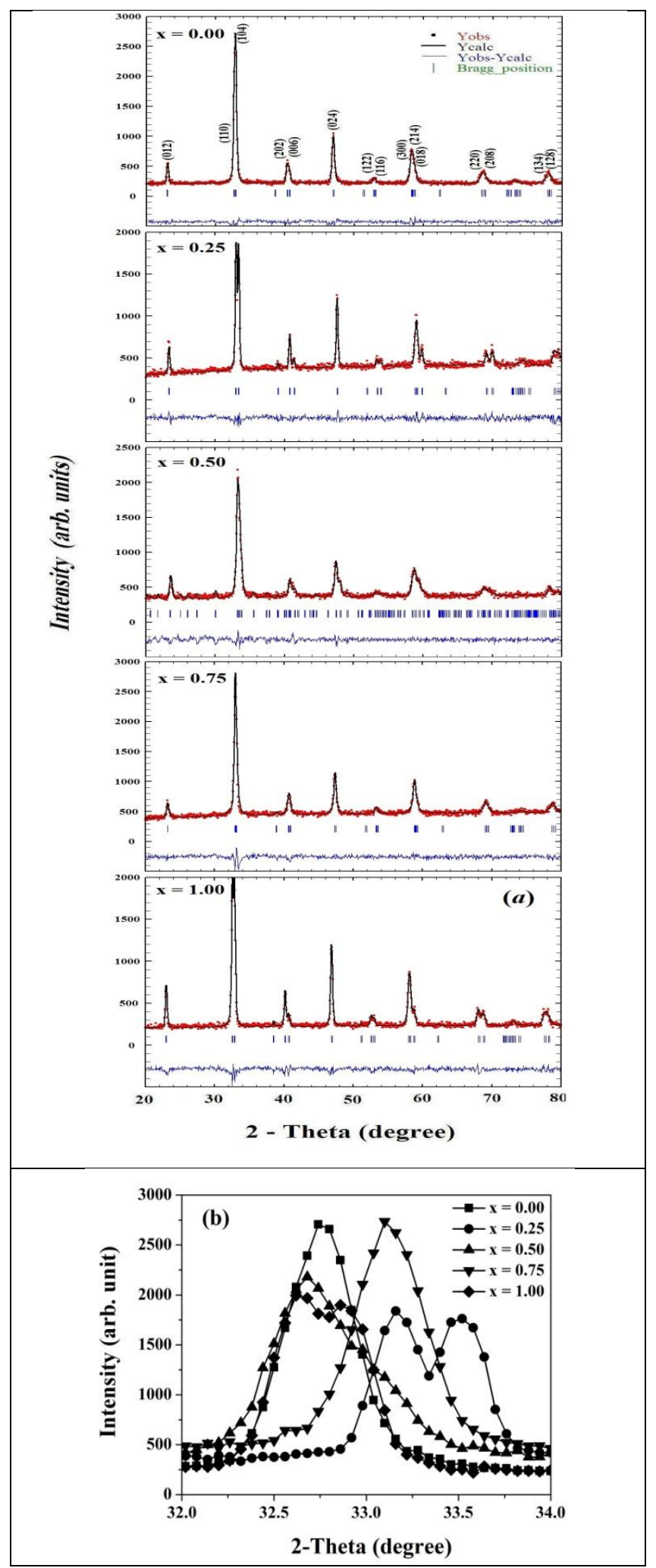


Fig. 2:

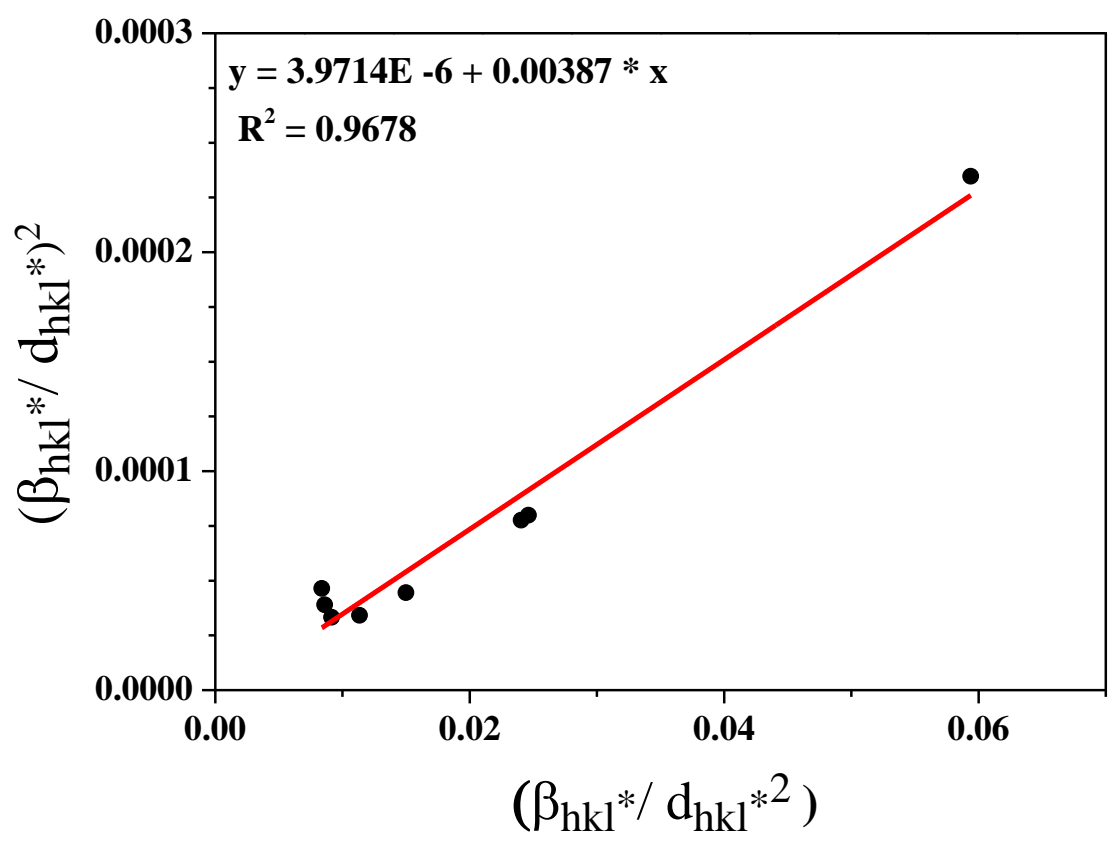

Fig. 3:

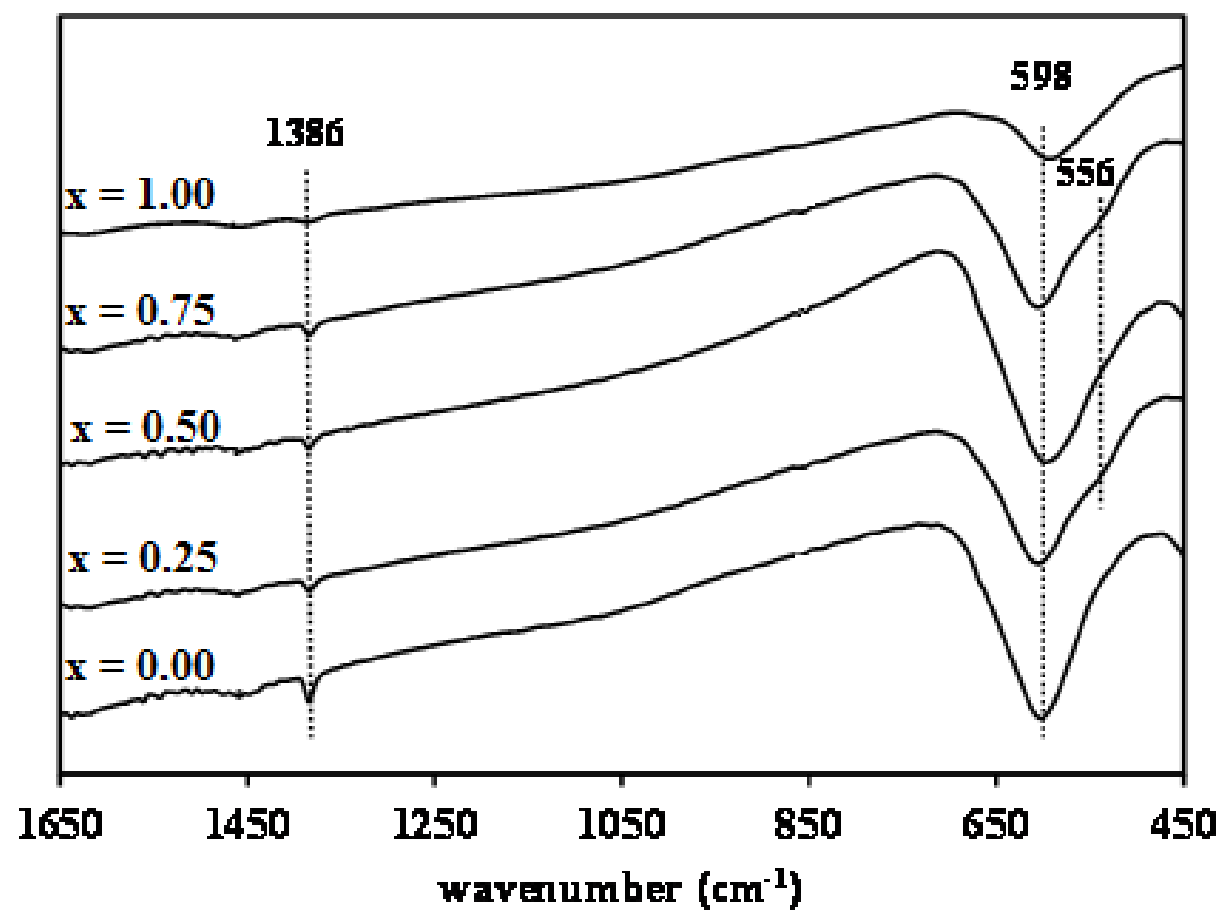


Fig. 4:

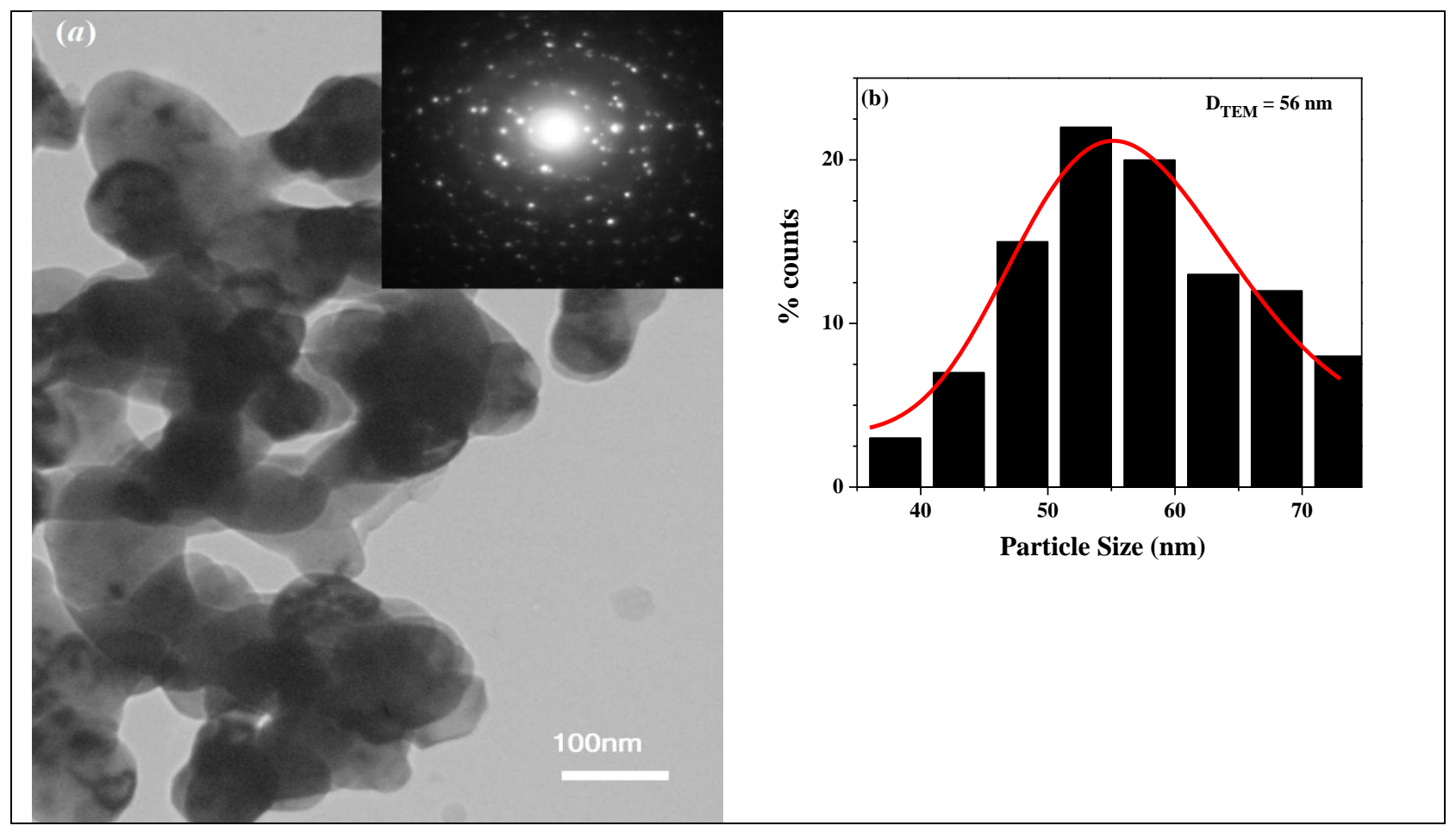

Fig. 5:

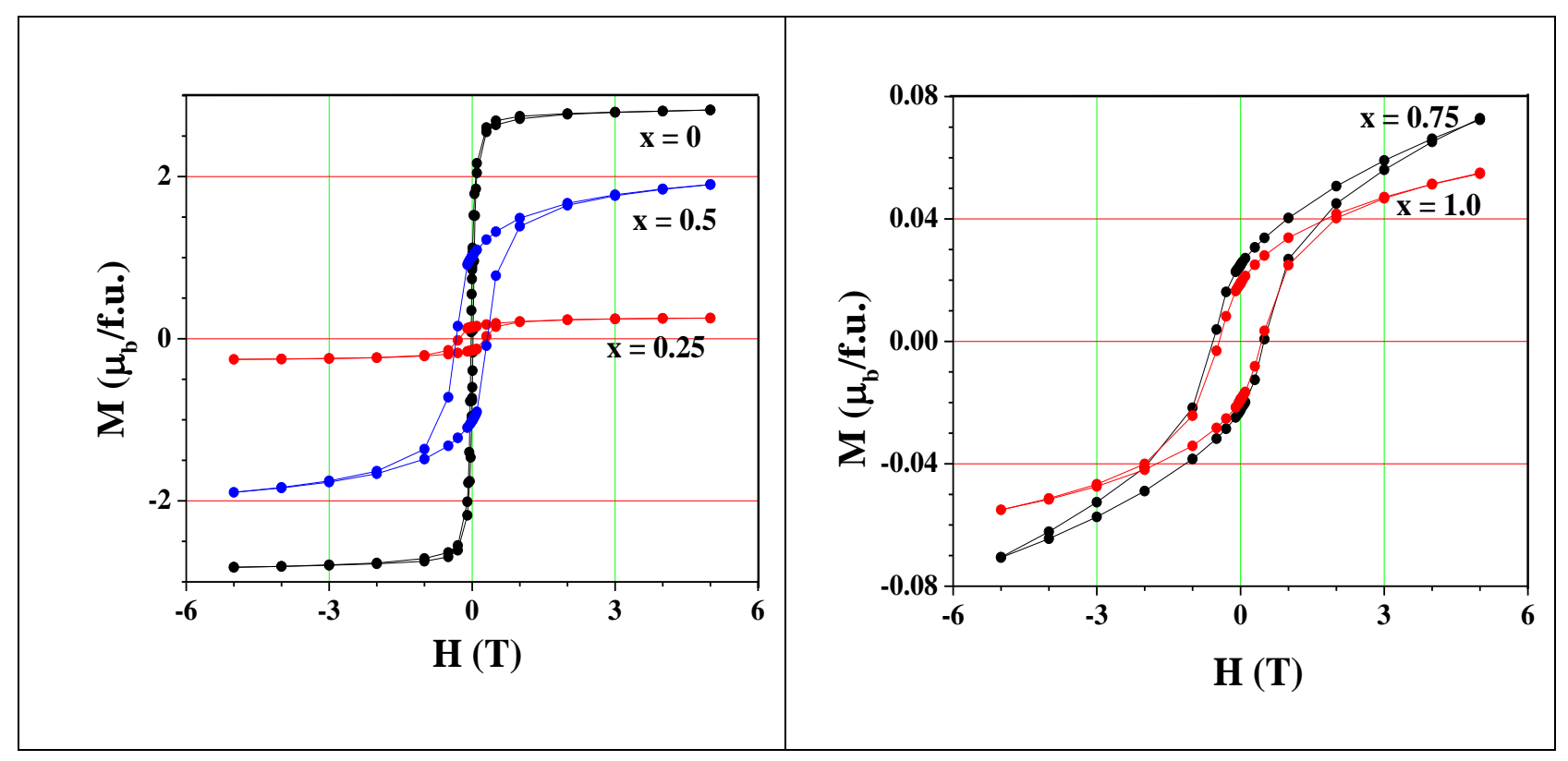


Fig. 6:

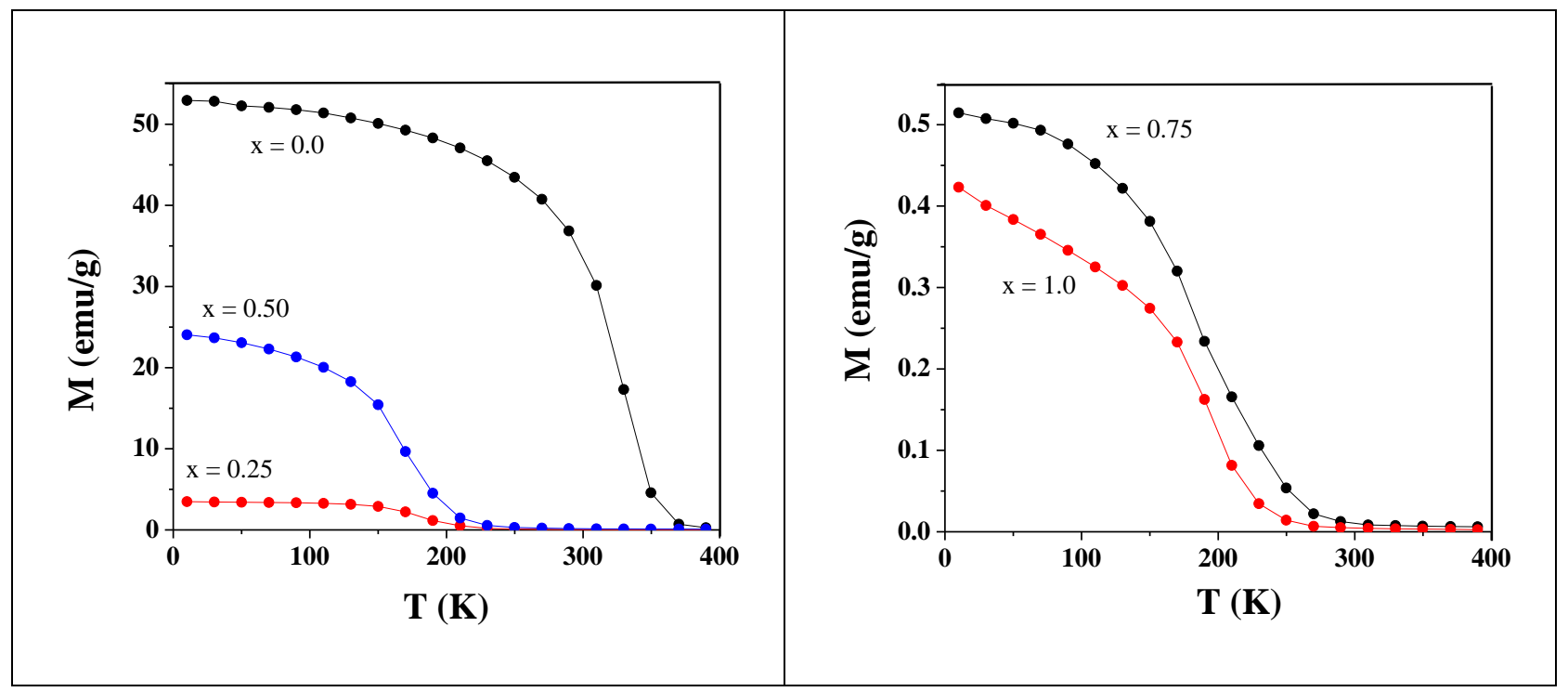

Fig. 7:

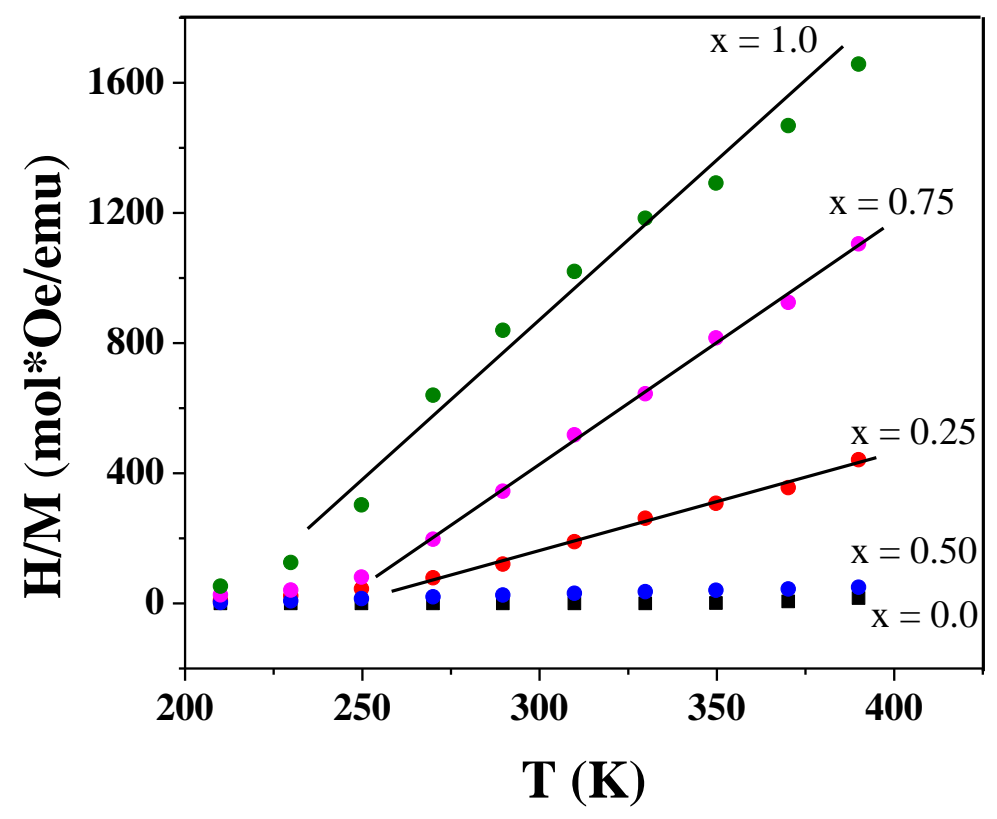


Fig. 8:

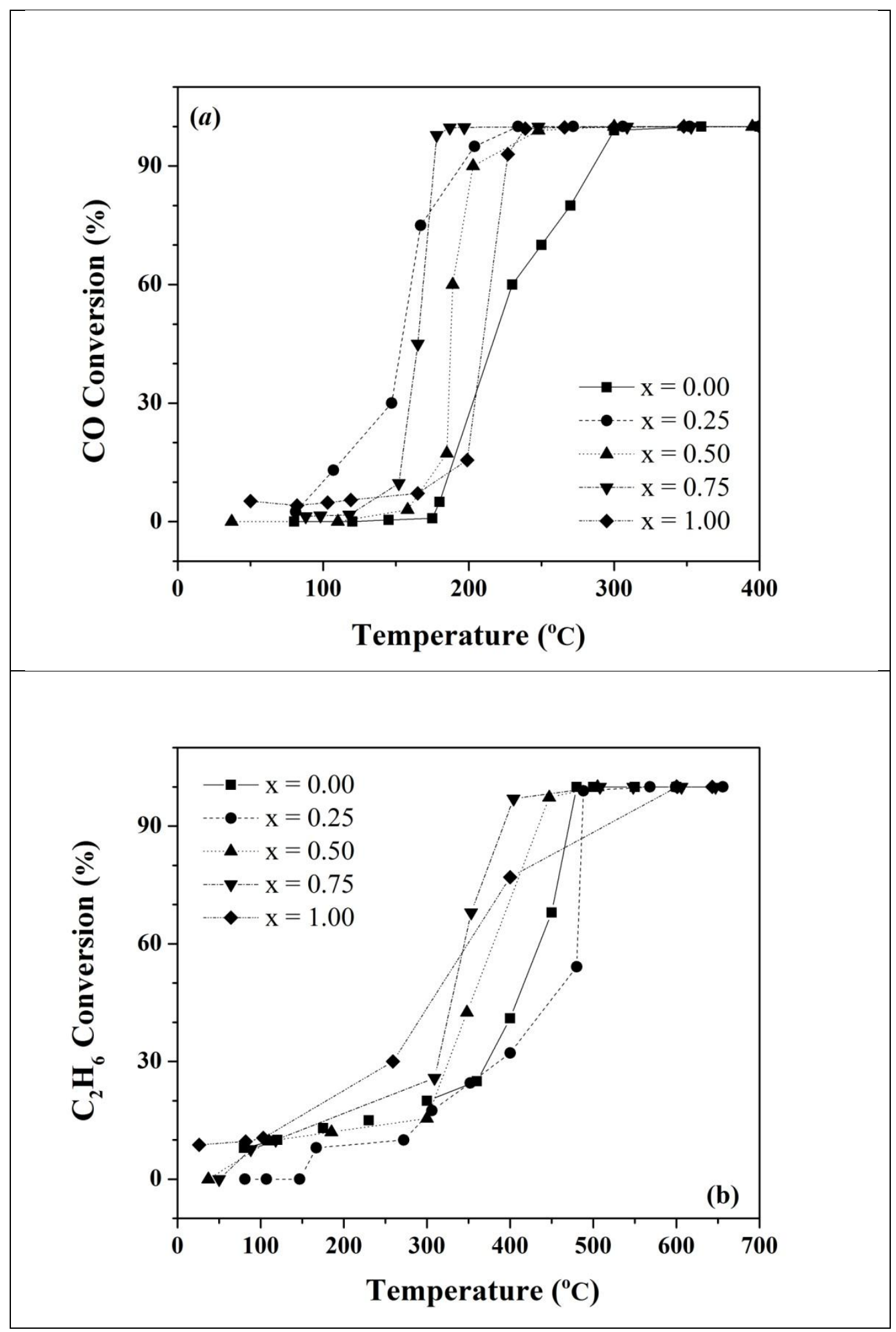

